NASZA DERMATOLOGIA Onlin OUR DERMATOLOGY Online

Source of Support: Georgia Dermatopathology Associates, Atlanta, Georgia, USA (MSH, AMAV).

Competing Interests: None

\section{AUTOIMMUNE EPIDERMAL BLISTERING DISEASES}

\author{
Ana Maria Abreu Velez ${ }^{1}$, Juliana Calle ${ }^{2}$, Michael S. Howard ${ }^{1}$ \\ ${ }^{1}$ Georgia Dermatopathology Associates, Atlanta, Georgia, USA \\ ${ }^{2}$ Department of Dermatology, University of Antioquia, Medellin, Colombia, SA.
}

Corresponding author: Ana Maria Abreu Velez, MD PhD

abreuvelez@yahoo.com

\begin{abstract}
Autoimmune bullous skin diseases (ABDs) are uncommon, potentially fatal diseases of skin and mucous membranes which are associated with deposits of autoantibodies and complement against distinct molecules of the epidermis and dermal/epidermal basement membrane zone (BMZ). These autoantibodies lead to a loss in skin molecular integrity, which manifests clinically as formation of blisters or erosions. In pemphigus vulgaris, loss of adhesion occurs within the epidermis. The pioneering work of Ernst H. Beutner, Ph.D. and Robert E. Jordon, M.D. confirmed the autoimmune nature of these diseases. Walter F. Lever, M.D. contributed significantly to our understanding of the histopathologic features of these diseases. Walter Lever, M.D. and Ken Hashimoto, M.D. contributed electron microscopic studies of these diseases, especially in pemphigus vulgaris and bullous pemphigoid. In bullous pemphigoid (BP), linear IgA bullous dermatosis, epidermolysis bullosa acquisita (EBA) and dermatitis herpetiformis (DH), loss of adhesion takes place within or underneath the BMZ. Classic EBA demonstrates extensive skin fragility; DH is commonly associated with gluten-sensitive enteropathy, and manifests clinically with pruritic papulovesicles on the extensor surfaces of the extremities and the lumbosacral area. The clinical spectrum of bullous pemphigoid includes tense blisters, urticarial plaques, and prurigo-like eczematous lesions. Pemphigoid gestationis mostly occurs during the last trimester of pregnancy, and mucous membrane pemphigoid primarily involves the oral mucosa and conjunctivae and leads to scarring. Linear IgA bullous dermatosis manifests with tense blisters in a „,cluster of jewels”-like pattern in childhood (chronic bullous disease of childhood) and is more clinically heterogeneous in adulthood. Many of the autoantigens in these disorders are known and have been well characterized. ABDs may be influenced by both genetic and exogenous factors. The diagnoses of ABDs is based on histology of lesional skin and direct immunofluorescence (DIF) of perilesional skin, as well as by serologic confirmation of autoantibodies by indirect immunofluorescence (IIF) and recombinant autoantigens. The titers of the autoantibodies may correlate with the disease severity, and can be measured by indirect immunofluorescence and by ELISA testing. Therapeutically, systemic treatment with glucocorticoids is combined with immunosuppressive adjuvants which allow for fast reduction of systemic steroids. A prospective clinical trial in pemphigus showed that adjuvant treatment with azathioprine, mycophenolate mofetil and cyclophosphamide led to a significant reduction of the cumulative dose of systemic steroids until complete clinical remission was achieved. In bullous pemphigoid, topical treatment with clobetasol can help to accomplish a clinical remission without the major side effects seen with systemic steroids. Also, therapeutic depletion of B lymphocytes by rituximab has considerably improved the overall prognosis of pemphigus. Nurses and other paramedical personal caring for patients with these disorders play a critical role in improving the quality of life of the patients and their families. The patients need to be continuously evaluated to avoid secondary infections, especially if they have long term immuosupressive treatment.
\end{abstract}

Key words: autoimmune blistering skin diseases; bullous pemphigoid (BP); cicatricial pemphigoid (CP); basement membrane zone (BMZ); pemphigus vulgaris (PV); dermatitis herpetiformis (DH)

Abbreviations and acronyms: Bullous pemphigoid (BP), immunohistochemistry (IHC), direct and indirect immunofluorescence (DIF and IIF), hematoxylin and eosin (H\&E), antibody (Ab), basement membrane zone (BMZ), intercellular staining between epidermal keratinocytes (ICS), pemphigus vulgaris (PV), cicatricial pemphigoid (CP), subcorneal pustular dermatosis (SCPD), dermatitis herpetiformis (DH), sodium dodecyl sulfate (SDS), SDS polyacrylamide gel electrophoresis(SDS-PAGE), autoimmune blistering skin diseases (ABDs), fogo selvagem (FS), endemic pemphigus foliaceus in El-Bagre, Colombia (El Bagre-EPF), desmogleins 1 and 3 (Dsg1 and Dsg3), nonkeratinizing squamous metaplasia (SM). 


\section{Introduction}

Autoimmune bullous skin diseases (ABDs) are uncommon, potentially fatal diseases of skin and mucous membranes which are associated with deposits of autoantibodies and complement against distinct molecules of the epidermis and dermal/epidermal basement membrane zone (BMZ). These autoantibodies lead to a loss in skin molecular integrity, which manifests clinically as formation of blisters or erosions. In pemphigus vulgaris, loss of adhesion occurs within the epidermis. The pioneering work of Ernst H. Beutner, Ph.D. and Robert E. Jordon, M.D. confirmed the autoimmune nature of these diseases. Walter F. Lever, M.D. contributed significantly to our understanding of the histopathologic features of these diseases. Walter Lever, M.D. and Ken Hashimoto, M.D. contributed electron microscopic studies of these diseases, especially in pemphigus vulgaris and bullous pemphigoid. In bullous pemphigoid (BP), linear IgA bullous dermatosis, epidermolysis bullosa acquisita (EBA) and dermatitis herpetiformis $(\mathrm{DH})$, loss of adhesion takes place within or underneath the BMZ. Classic EBA demonstrates extensive skin fragility; $\mathrm{DH}$ is commonly associated with gluten-sensitive enteropathy, and manifests clinically with pruritic papulovesicles on the extensor surfaces of the extremities and the lumbosacral area. The clinical spectrum of bullous pemphigoid includes tense blisters, urticarial plaques, and prurigo-like eczematous lesions. Pemphigoid gestationis mostly occurs during the last trimester of pregnancy, and mucous membrane pemphigoid primarily involves the oral mucosa and conjunctivae and leads to scarring. Linear IgA bullous dermatosis manifests with tense blisters in a „cluster of jewels"-like pattern in childhood (chronic bullous disease of childhood) and is more clinically heterogeneous in adulthood. Many of the autoantigens in these disorders are known and have been well characterized. ABDs may be influenced by both genetic and exogenous factors. The diagnoses of ABDs is based on histology of lesional skin and direct immunofluorescence (DIF) of perilesional skin, as well as by serologic confirmation of autoantibodies by indirect immunofluorescence (IIF) and recombinant autoantigens. The titers of the autoantibodies may correlate with the disease severity, and can be measured by indirect immunofluorescence and by ELISA testing. Therapeutically, systemic treatment with glucocorticoids is combined with immunosuppressive adjuvants which allow for fast reduction of systemic steroids. A prospective clinical trial in pemphigus showed that adjuvant treatment with azathioprine, mycophenolate mofetil and cyclophosphamide led to a significant reduction of the cumulative dose of systemic steroids until complete clinical remission was achieved. In bullous pemphigoid, topical treatment with clobetasol can help to accomplish a clinical remission without the major side effects seen with systemic steroids. Also, therapeutic depletion of B lymphocytes by rituximab has considerably improved the overall prognosis of pemphigus. Nurses and other paramedical personal caring for patients with these disorders play a critical role in improving the quality of life of the patients and their families. The patients need to be continuously evaluated to avoid secondary infections, especially if they have long term immuosupressive treatment.

\section{Skin autoimmune bullous diseases}

In 1881, Auspitz coined the term ,acantholysis”, and claimed it to be one of the early disease hallmarks of pemphigus. In 1884, Duhring distinguished dermatitis herpetiformis from pemphigus. In 1943, Civatte gave a histologic review of the process of acantholysis, greatly contributing to our understanding of cutaneous bullous diseases [1]. He further observed that acantholysis was absent in dermatitis herpetiformis and erythema multiforme. In 1949, Tzanck and Aron Brunetire demonstrated that scrapings from the floor of pemphigus vulgaris blisters showed typical acantholytic cells (large round epidermal cells which had no intercellular bridges remaining) [2]. Their cutaneous cytologic testing was based on Civatte's finding of degenerated epidermal cells in the bullae of pemphigus. In 1953, Lever distinguished bullous pemphigoid from many other blistering diseases by showing that the bullae of pemphigoid were subepidermal, and that acantholysis was absent [3,4]. In 1959, steroids were introduced for the treatment of pemphigus vulgaris and bullous pemphigoid, with a significant reduction in morbidity and mortality.

Current concepts of skin autoimmune bullous diseases (ABDs) also advanced around 1965 by confirmation of the autoimmune nature of these diseases, precise histologic characterizations of the level of the blisters and through electron microscopic analysis [3-21].

ABDs are uncommon disorders, and may be chronic and/or lethal. These diseases should be recognized by dermatologists, pediatricians, general physicians, ophthalmologists, pathologists, dermatopathologists, otolaryngologists, dentists, and obstetricians/gynecologists.

As previously noted, the current classification of ABD blisters, as well as the precise location of deposits of the autoantibodies and complement was pioneered by Drs Walter Lever, Ken Hashimoto, Ernst Beutner and Robert Jordon [12,13]. Those ABDs that have deposits of autoantibodies and/or complement located within the epidermis belong largely to the pemphigus disease group. In contrast, ABDs whose autoantibodies and/ or complement are classically directed sub-epidermally are classified in the pemphigoid group [9-20]. Most of the autoantigens in these diseases have been characterized at the molecular level; however, the precise mechanisms that trigger production of the disease autoantibodies are not known. The clinical, immunologic and epidemiologic spectrum of these diseases is broad [1-20]. In general, therapy is directed at controlling downstream disease events rather than controlling initial pathologic processes.

\section{Epidermal autoimmune diseases \\ Pemphigus}

The term pemphigus defines a group of autoimmune interepithelial blistering diseases that are characterized by loss of normal cell-cell adhesion (acantholysis), and by the presence of pathogenic (predominantly IgG) autoantibodies reacting against epithelial adhesion molecules. Pemphigus is further divided in two major subtypes: pemphigus vulgaris $(\mathrm{PV})$ and pemphigus foliaceus (PF). However, several other disorders such as IgA pemphigus, IgE pemphigus, pemphigus herpetiformis, drug induced pemphigus, Senear Usher syndrome and endemic pemphigus foliaceus exist; further, some researchers have described possible endemic forms of PV [1-2,9-10,12-13,1618]. A less common form of pemphigus is the paraneoplastic form (PNP) [22]. PNP is characterized by autoantibodies which immuoprecipitate a group of peptides synthesized by keratinocytes, including BP230, desmoplakin, envoplakin and other 170 and $190 \mathrm{kDa}$ antigens. (Tabl. I). 


\begin{tabular}{|l|l|l|l|}
\hline $\begin{array}{l}\text { Hereditary intraepidermal } \\
\text { blistering diseases }\end{array}$ & $\begin{array}{l}\text { Bacterial and viral intraepidermal } \\
\text { blistering diseases }\end{array}$ & $\begin{array}{c}\text { Other intraepidermal } \\
\text { blsitering diseases }\end{array}$ & \multicolumn{1}{|c|}{ Vesicants, sunlight and others } \\
\hline $\begin{array}{l}\text { Bullous congenital ichthyosiform } \\
\text { erythoderma }\end{array}$ & $\begin{array}{l}\text { Bullous impetigo, staphlococcal scalded } \\
\text { skin syndrome/SSSS. }\end{array}$ & $\begin{array}{l}\text { Miliaria crystallina } \\
\text { Bullides, arsenic, organic mercury and } \\
\text { organic isothiocyanates. }\end{array}$ \\
\hline Bullous ichthyosis of Siemens & $\begin{array}{l}\text { Herpesvirus infections, including herpes } \\
\text { viruses 1 and 2, and varicella zoster. }\end{array}$ & Friction blisters. & Sun and ultraviolet radiation. \\
\hline $\begin{array}{l}\text { Incontinentia pigmentii } \\
\text { (vesicular stage) }\end{array}$ & Hand foot and mouth disease. & Hydroa vacciniforme. & $\begin{array}{l}\text { Cantharidin, ricin, methoxalem, } \\
\text { podophyllin, toxins from snake and other } \\
\text { animal bites, thermal blisters }\end{array}$ \\
\hline
\end{tabular}

Table I. Diseases or conditions with intraepidermal blisters, excluding autoinmune skin diseases.

\section{Pemphigus vulgaris (PV)}

(OMIM 169610) PV is a rare vesiculobullous condition which accounts for a large number of the cases of pemphigus [1,2]. Its incidence is approximately $0.1-1.0$ per 100,000 /year $[1,2$, 9-10]. PV is the common form of pemphigus; the prevalence of $\mathrm{PV}$ is high in regions with a predominant Jewish population. PV is a potentially lethal autoimmune blistering disorder, involving both skin and mucous membranes [3-10]. A slight female predominance has been reported in the disease. The mean age of onset is 50-60 years; however, the range is broad, and disease onset in older individuals and in children has been documented. The Nikolsky clinical sign is usually present in patients with active blistering; specifically, firm, lateral sliding pressure fractures a normal-appearing epidermis, producing an erosion. The Nikolsky sign is not specific for pemphigus vulgaris, and is also found in other active cutaneous blistering diseases. The PV diagnosis is confirmed by the following criteria: typical clinical lesions, a histologic demonstration of loss of adhesion in the epidermis with intraepidermal blister formation and acantholysis; and demonstration of IgG antibodies bound to the cell surfaces of affected keratinocytes. As noted, patients with pemphigus vulgaris commonly suffer from mucosal involvement; the mucosal involvement may precede cutaneous manifestations by months, or may represent the sole manifestation of the disease. In the mid- to late 1980s, the target antigens of pemphigus were characterized by immunochemical methods, including immunoprecipitation (IP) and immunoblotting (IB). Further characterization occurred in the 1990 s, by isolation of the cDNA for pemphigus antigens; these studies demonstrated that the target antigens in pemphigus are desmogleins. Patients with PV possess antibodies directed against desmoglein 3, a $130 \mathrm{kDa}$ transmembrane glycoprotein, and expressed only in the stratified squamous epithelia; the target protein belongs to the desmosomal cadherin family of cell adhesion molecules [23-26]. Further, a heterogeneous autoantibody population has been encountered in many PV sera, including to Dsg1 [23-30]. Dsg1 is a calcium-dependent cell adhesion molecule. Autoantibodies against plaque related keratiocyte proteins, including periplakin, envoplakin and desmoplakin dominate in mucosal PV, and also in dogs [32,33]. New techniques, such as antibody profiling by proteomic tehniques have been used for testing additional putative PV antigens. A recent study tested 264 pemphigus sera and 138 normal control sera on a multiplexed protein array platform; this platform contained 701 human genes encompassing many known keratinocyte cell surface molecules and members of protein families targeted by non-organ specific PV antibodies [34]. The top 10 antigens recognized by the majority of the test patient's sera were proteins encoded by the desmocollin 1 and 3 (DSC1, DSC3),
ATP2C1, PKP3, CHRM3, COL21A1, ANXA8L1, CD88 and CHRNE genes. The most common combinations of target antigens included 1) at least one of the adhesion molecules DSC1, DSC3 or PKP3 and/or 2) the acetylcholine receptor CHRM3 or CHRNE with or without 3 ) the MHC class II antigen DRA. The authors sorted the data based on a ratio of patient to control frequencies of antigen recognition that exceeded 1:10. The most common antigens were molecules encoded by the CD33, GP1BA, CHRND, SLC36A4, CD1B, CD32, CDH8, CDH9, PMP22 and HLA-E genes, as well as mitochondrial proteins encoded by the NDUFS1, CYB5B, SOD2, PDHA1 and FH genes. The highest specificity combinations for PV were autoantibodies to the calcium pump encoded by ATP2C1 with a C5a receptor, plus DSC1, DSC3 or HLA-DRA [34]. A second group of authors had previously reported similar testing using protein array technology, and described positivity towards with 16 antigens; most of these were cell-surface proteins such as CD2, CD31, CD33, CD36, CD37, CD40, CD54, CD66c and CD84 molecules, nicotinamide/nicotinic acid mononucleotide adenylyltransferase, immunoglobulin heavy chain constant region gamma 2 and others. [35]. Overall, the sensitivity of these investigative techniques seems to be high; however, the specificity needs further evaluation.

\section{PV affects mucosae}

In the mouth, extensive painful erosions may result in decreased food and drink intake. Involvement of the throat can produce hoarseness, and difficulty swallowing. The esophagus, conjunctiva, nasal mucosa, vagina, penis, anus and labia may also be involved. Often the presenting lesions of PV are oral lesions, which may lead to periodonitis (plaque-induced gum inflammation); these lesions should be recognized and treated. The treatment should be coordinated with orthodontists, periodontists and oral surgeons as warranted. .Disease associated gum plaque hygiene is critical in preventing periodontal infection in PV patients. These patients should be informed about the risk of periodontitis and other oral and laryngeal esophageal complications, and encouraged to pursue long-term periodontal follow up. One of the more important differential diagnoses of oral PV is drug induced oral lesions. Although less common than those affecting the skin, adverse drug reactions involving the mouth are quite frequent. A high index of suspicion assists in the diagnosis of these drug reactions, as they may mimic other disease states such as oral aphtae, erythema multiforme, xerostomia, lichen planus and pemphigus [36-39]. Other reactions such as gingival hyperplasia secondary to the administration of phenytoins, nifedipine or cyclosporine are well known and clinically characteristic. 
Behcet's disease may also lie in the diferential diagnosis. ,The pathogenic mechanisms of oral reactions to drug administration are similar to those causing adverse drug reactions in the skin. To diagnose oral adverse drug reactions, a clinical interview is necessary including a detailed drug history and identification of any nonprescription and herbal medicines.

The lower urinary tract also seems to be involved in patients with ABDs. In one study, fourteen patients diagnosed with ABDs underwent video-recorded urethrocystoscopy: 9 patients (7 women and 2 men) with PV, 4 patients (2 women and 2 men) with BP and 1 female patient with mucous membrane pemphigoid. None of the 14 patients complained of lower urinary tract symptoms. The urethrocystoscopy disclosed characteristic lower urinary tract lesions in almost every patient with ABDs (13 of 14 patients; 93\%). Two partially overlapping pathologic patterns prevailed: 1) nonkeratinizing squamous metaplasia (SM), found in $64 \%$ of the patients, including 2 of 4 men; and 2) mucosal inflammation of the bladder base/trigone that extended-especially among male patients-to the proximal urethra ( $64 \%$ of the patients). SM prevailed among patients with pemphigus vulgaris; the inflammatory lesions among patients with BP, and involvement of proximal urethra among male patients. The authors presented urethrocystoscopic evidence that inflammatory urothelial lesions of the bladder and proximal urethra and/or with nonkeratinizing SM of the trigone area are almost invariable findings in patients with ABDs. Studies focusing on the pathophysiology of bladder lesions in these patients may contribute to a better understanding of both the pathology of bullous skin diseases, and the pathobiology of urinary bladder urothelium [40].

Conjuctival lesions have been also associated with PV. Most commonly, the disease begins in the oral cavity and spreads to other areas including the conjunctiva and eyelids. True ocular bulbar involvement is rare, and likely underdiagnosed. Some of the ocular findings have included conjunctivitis and marginal eyelid erosion. In addition, a diffuse conjunctival hyperemia with an area of bulbar conjunctival erosion has been documented in the anterior segment of the eye. As with the oral manifestations of systemic PV, ocular findings may imply severe disease and require a multidisciplinary approach $[41,42]$. In clinical similarity, rectal lesions and toxic dilatation of the colon have been also described in patients with PV $[43,44]$.

The histopathologic hallmark of PV is a suprabasilar epidermal acantholytic blister; the roof is formed by most of the epidermis, possibly as result of transudative fluids accumulating between epidermal keratinocytes and the basement membrane zone (BMZ). These conditions produce a suprabasal epidermal split, forming a blister. Histopathology demonstrates an intraepidermal blister. The earliest histologic changes consist of intercellular edema, with loss of intercellular attachments in the basal layer. Suprabasal epidermal keratinocytes then separate from the basal layer cells to form clefts and blisters. Basal cells are separated from one another and stand like a row of tombstones on the floor of the blister, but they remain attached to the basement membrane zone. Blisters contain some acantholytic cells. The associated dermal infiltrate is found mainly in perivascular areas, and classically consists of lymphocytes, neutrophils and few eosinophils. Histopathology can help differentiate pemphigus vulgaris from pemphigus foliaceus, which demonstrates a more superficial epidermal cleavage; often the dermal papillae are edematous, with dilatation of blood vessels and extravasation of inflamamtory cells including neutrophils; a variable amount of serous infiltration of the dermis is noted. A Tzanck preparation is a smear taken from the base of a blister or oral erosion, which may contain acantholytic cells. Histologic blistering is preceded by eosinophilic spongiosis in some patients. In 1952, Dr. Director reported for the first time the characteristic "row of tombstones" that represents one the best histopathological features of this disease [45-46]. The PV diagnosis is then confirmed by the presence of $\operatorname{IgG}$ deposition on the surfaces of epidermal keratynocytes by direct immunofluorescence evaluation. Complement component C3, IgM, and IgA are not detected as often than $\mathrm{IgG}$, and their staining is less intense.

\section{Genetic factors}

Predisposition to pemphigus is linked to genetic factors [4754].Certain major histocompatibility complex (MHC) genes have been associated with PV. These include human leukocyte antigen (HLA) class I and class II molecules, in particular alleles of HLA-DR4 (DRB1*0402) and HLA-DRw6 (DQB1*0503). Non-classical HLA-E alleles, known to mediate natural killer cells and CD8 positive T-cell activity have also been also associated with PV [55].

Besides the genetic predisposing factors that have been associated with PV, stressful life events have been found to possibly play a role in triggering and/or worsening of pemphigus $[56,57]$. Thus psychological care is included in management of these patients [57]. One study searched for triggering factors, including occupational exposures and personal habits in the etiopathogenesis of PV. The authors found that occupational exposure to pesticides was significantly higher in patients with pemphigus $(14.8 \%)$ than in controls $(5.4 \%)$; patients with pemphigus were exposed to pesticides three times more often than were healthy subjects [58]. Other studies have shown exposure to chemicals and pesticides and long-term sun exposure to be possible triggering factors in PV [59]. Sun exposure and high temperatures have been implicated in increasing the severity of the disease.

\section{Fluorescent antibody technique}

Beutner and Jordon provided the earliest data pertinent to this technique, with the demonstration of antiepithelial autoantibodies in the sera of patients with pemphigus and bullous pemphigoid. The basic theory of the fluorescent antibody technique is simple. Antigenic material present in the tissue (e.g. in the cells, at cell margins, or at the basement membrane zone) will react specifically with its related antibody. The immunopathologic reaction then results in deposits of minute amounts of disease specific antibodies over the areas of a tissue section where the antigen is present. When correlating anti-antibody antibodies have previously been marked with fluorescent markers, microdeposits of these correlating fluorescent antibodies are visible under a fluorescent microscope [9-12].

\section{Indirect immunofluorescence testing (IIF)}

In indirect immunofluorescence (IIF) testing, is utilized to obtain titers of disease autoantibodies. The serum autoantibody itself not labelled; a fluorescent marker is carried by a second antibody, having specificity for the pathologic autoantibody immunoglobulin which has been fixed to antigen(s) in a normal human skin substrate. The indirect immunofluorescent test is thus more sensitive, and results in a brighter staining than the direct test, because it is capable of attaching more fluorescent label per antigenic site. 
For testing, sera are serially diluted with isotonic saline, starting with a 1:10 dilution. The autoantibody titer is considered the highest dilution of patient serum which gives a positive immunofluorescent test. A testing dilution of labelled antihuman gamma globulin is also utilized; this fluorescent labelled antibody is commercially available. It is usually prepared by injecting suitable animals with purified human gamma globulins. After a time interval the hyperimmune animal blood is collected. The generated animal antibody is then extracted, and chemically combined with a fluorescent dye. To perform IIF, the substrate is prepared by quick-freezing in liquid nitrogen, without chemical fixation which would change the immunologic reactivity of the substrate antigenic material. Four micron sections are cut in a cryostat and placed on a glass slide. The tissue section is first washed thoroughly, and then one or two drops of a dilution of untreated patient serum are placed on the sections; the sections are then incubated at room temperature in a moist chamber for at least 30 minutes. Excess patient serum is removed by washing with phosphate-buffered saline. The rinsed tissue section is then covered with one or two drops of fluorescent chromogen-tagged antihuman testing immunoglobulin, and again incubated and washed. The sections are then microscopically examined for fluorescence [9-12].

\section{Direct immunofluorescence testing (DIF)}

In contradistinction to the above, in the direct immunofluorescent test, the labelled testing antibody reacts directly with patient skin tissue as substrate. The labelled testing antibody may be derived from the patient or from other sources. To perform DIF, the patient's skin section is overlaid with one or two drops of a dilution of labelled testing antiserum directed against any disease antibodies attached in the patient skin substrate. Thus, the distinguishing difference between IIF and DIF is the position of the labelled testing antibody during the test. In DIF, the labelled testing antibody is attached to the patient disease autoantibodies, located on the patient skin. In IIF, the labelled testing antibody is attached to patient disease antibodies which have been bound to a normal human skin substrate [9-12]. For the best methods of handling the biopsies, deciding the sites of the biopsies and processing the serum, please consult Immunopathology of the skin. E.H.Beuter,T.P. Chozelski, S.F. Bean and R.E Dowden, Editors.

\section{Immunoblotting}

The Western blot, or protein immunoblot (IB) is a widely accepted analytic technique used to detect specific proteins in a sample of tissue homogenate or extract. The method was used to discover many of the pemphigus antigens. It utilizes gel electrophoresis to separate native proteins by their three dimensional structures, or denatured proteins by the length of their polypeptides. The proteins are then transferred onto a membrane (typically nitrocellulose or PVDF), where they are stained with antibodies specific to the target protein. Initially, the samples can be obtained from whole tissue, or from cell culture. In pemphigus investigations, bovine snouts, skin and tongue have been common antigen sources. In brief, the solid tissues are first broken down mechanically using a blender (for larger volumes), a homogenizer (smaller volumes) or by sonication (sound). Cells may also be broken open by one of these mechanical methods. Detergents, salts, and buffers are also used to improve cell lysis, and to solubilize proteins. Protease and phosphatase inhibitors are often added to prevent the digestion of the sample by its own enzymes. The proteins of the samples are then separated via gel electrophoresis. The separation of proteins may occur utilizing their isoelectric points, their electric charges, their molecular weights, or by a combination of these methods. Thus, gel electrophoresis is a very useful way to identify proteins and is a common technique used in research laboratories where cutaneous blistering diseases are studied. The most common type of gel electrophoresis uses polyacrylamide gels and buffers including sodium dodecyl sulfate (SDS-PAGE; SDS polyacrylamide gel electrophoresis). The samples are loaded into wells in the gel with one or more lanes to add molecular weight standards. When voltage is applied along the gel, the proteins migrate within the gel and separate into bands within each lane. The separated proteins are then transferred from the gel onto a membrane made of nitrocellulose or polyvinylidene difluoride (PVDF). PVDF is technically better for protein sequencing studies. The transfer onto the membranes is termed electroblotting, and uses an electric current to pull proteins from the gel onto the PVDF or nitrocellulose. The transfer of the proteins from the gel onto the membrane can be confirmed by staining the membrane with Coomassie Brilliant Blue or Ponceau S dyes. Next, the membranes are blocked and test antibodies (ie, the patient's serum) are added to the membranes. Additionally, IB antibody detection methods require the usage of secondary antibodies directed against human antigens linked to biotin, or to a reporter enzyme such as alkaline phosphatase or horseradish peroxidase. Most commonly, a horseradish peroxidase-linked secondary antibody is used to cleave a chemiluminescent agent, and the reaction product produces luminescence in proportion to the amount of protein. Finally, a sensitive sheet of photographic film is placed against the membrane, and exposure to the light from the reaction creates an image of the antibodies bound to the IB. Alternatively, a radioactive signal may be utilized to quantify the amount of protein. Finally, a cheaper but less sensitive approach utilizes a 4-chloronaphthol staining with $1 \%$ hydrogen peroxide; reaction of the peroxide radicals with 4-chloronaphthol then produces a dark purple stain that can be photographed without using sensitive photographic film, and/or submitted to colorimetric analysis [24,26-30].

\section{Enzyme linked immunosorbent assay (ELISA)}

Detecting autoantibodies in PV and PF sera is possible using ELISA testing. ELISA testing may utilize recombinant forms of Dsg3 and Dsg1, and conformational and linear epitopes obtained from bovine snout tissue as an antigen source. Notably, disease activity correlates with ELISA antibody titers in most patients [60-63]. Multiple ELISA assays are commercially available; however, the initial ELISAs did have some problems with grey zone positivity and with nonpathogenic anti-desmoglein 3 antibodies found in selected PV patient's sera [64]. ELISA improvements have thus been made; an ethylenediaminetetraacetic acid (EDTA)-treated ELISA was found to detect only non-pathogenic anti-Dsg3 antibodies directed against non-calcium $(\mathrm{Ca}++)$-dependent PV epitopes [62]. Also, meta-analyses have been performed to estimate the diagnostic accuracy of ELISA to detect anti-BP180 and antiDsg3 autoantibodies in the diagnosis of autoimmune blistering skin diseases. A large review was conducted of Medline English written articles published between 1994 and 2011, reporting data on the sensitivity and specificity of ELISA diagnostic tests. 
Reviewed articles were then evaluated according to the quality of the statistical methods used to calculate diagnostic accuracy (ie, definitions of cutoff value, use of ROC curves, and selection of control cases). The meta-analysis was performed using a summary ROC (SROC) curve and a random-effect model to independently combine sensitivity and specificity across studies. The results of the meta-analysis demonstrated that ELISA tests for anti-BP180 and anti-Dsg3 autoantibodies have high sensitivity and specificity for BP and PV respectively, and can be confidently used in daily laboratory practice for the initial diagnosis of autoimmune blistering skin diseases [63] (Fig. 1).
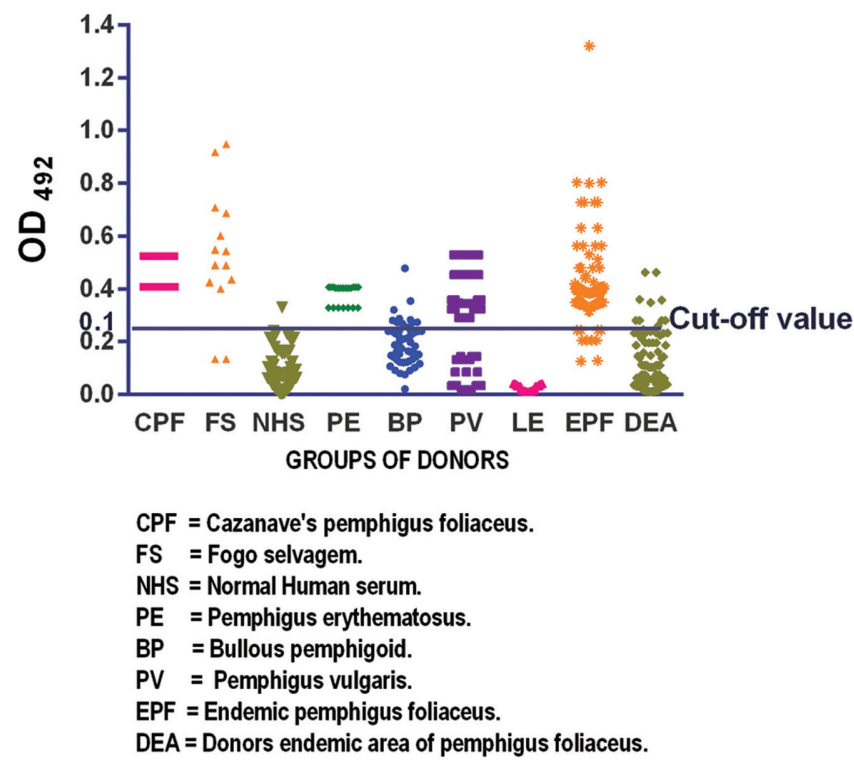

Figure 1. Comparison for the presence of autoantibodies against pemphigus foliaceus antigens (s), detected by this ELISA.

\section{Experimental animal studies}

Experimental animal studies on pemphigus were published years ago in non-English languages; thus, many were not indexed in Medline. The investigators injected antibodies with or without adjuvants into multiple animals, including mice and rabbits; these studies demonstrated temporary generation of autoantibodies and blisters, resembling the human disease in selected clinical, histopathologic and immunopathologic features. In the late 1980s and early 1990s, pemphigus autoantibodies were shown to have pathogenic activity in the blister induction in skin organ culture systems. The first reported studies in the English medical literature improved the animal model data, including findings of intercellular antibodies in all forms of pemphigus, and further studies on antigen isolation and animal immunization [60-64]. These advanced animal models confirmed pathogenic activity in the induction of blister formation in skin organ culture systems, as well as via passive transfer of patient $\operatorname{IgG}$ into neonatal animals. Further, multiple animal models have been created from these initial models; most of them use neonatal animals with thin skin, and none of these models have successfully demonstrated the chronicity of human pemphigus [65]. Finally, many animal models have been reported with null or transgenic mice that include complex immunological manipulations; in some cases, it is then difficult to distinguish pathologic findings, and what data is genuinely of scientific value [66-67].
Differential diagnosis of acantholysis. Multiple acantholytic cutaneous blistering diseases may resemble pemphigus. In brief, our differential includes Darier's disease, familial benign pemphigus/Grover's disease, Hailey-Hailey disease, viral vesicles and D-penicillamine associated related pemphigus-like lesions. Acantholysis may also be observed in actinic keratoses, squamous cell carcinomas, warty dyskeratomas and in focal areas of other tumors [7].

\section{Pemphigus vegetans/pyostomatitis vegetans}

In most of the current dermatologic lietarure, pemphigus vegetans is characterized as a variant of $\mathrm{PV}$, with lesional predilection of the axillae, groin, pubis, umbilical, submammary and perianal regions (ie, intertriginous areas) Dr Hallopeau initially described pemphigus vegetans in 1889 as pyodermitis vegetante, and believed it to represent a new clinicopathologic entity. In the same year, he changed his opinion to state that his, pyodermite vegetante' was in fact a suppurative variant of pemphigus vegetans $[68,69]$. Some of the contemporary dermatologists believed that these lesions described by Hallopeau (and subsequently by Hatzell, Jamieson, Fordyce and Gottheil) should be titled dermatitis vegetants or dermatitis herpetiformis. The lesions can present with or without oral compromise, and with or without abdomial sequelae such as ulcerative colitis, abdomial pain, diarrhea or proctitis. Some authors have highlighted the chronic nature of the disease, and the presence of diarrhea and other bowel involvement; these signs often precede the oral and skin manifestations. Primary oral presentations of pemphigus vegetans should also be recognized; two types are clinically documented: (a) The Neumann form, where flaccid blisters soon lead to areas of denudation, and then papillomatosis and hyperkeratosis. The buccal cavity is not often affected, but the vermilion borders of the lips often demonstrating vegetations and fissures, with secondary infections resulting in a characteristic appearance and odor. Some of the oral lesions show soft hyperplastic folds of mucosa, characterized by small miliary abscesses within superficial erosions (b). The less common clinical form, described by Hallopeau as pyodermite vegetante seems to affects younger patients and seems to have a better prognosis [68-76].

When oral lesions are present, there may be extensive areas of buccal denudation and the oral surface may become granular. Lesions are initially vesicles and pustules rather than bullae. In the oral cavity, these lesions may present as an erosive stomatitis. The vermilion borders of the lips often show a vegetating hyperplasia, with hypertrophic, fissured plaques exhibiting oozing and crusting; occasionally, the lesions can extend onto the nasal alae. Further, some cases of pemphigus vegetans classified as "pyostomatitis vegetans" have primarily involved the oral cavity. Since many of these patients have not been characterized with immunopathological testing, properly characterizing cases of pemphigus vegetans of Newman or Hallopeau may be difficult. Thus, upon analysis of their complete clinical, histologic, and immunofluorescent findings, some cases of pyostomatitis vegetans may need to be reclassified as oral manifestations of either pyoderma vegetans of Hallopeau, pemphigus vegetans of Hallopeau, or pemphigus vegetans of Neumann, although exact nosologic definitions of these diseases as separate entities are still controversial [68-76]. Histopathologic examination of patient's intertriginous area lesions has revealed papillomatosis and acantholysis, as well as suprabasilar clefting with acantholytic cells. 
The presence of microabscesses containing eosinophils can occasionally be seen. By direct immunofluorescence (DIF) examination, deposits of immunoglobulin IgG and complement/ C3 have been documented in some cases in the intercellular spaces of the epidermis. In the few cases has have been describe with finger nail lesions, histologic onycholysis and sterile pustules were noted with or without subungual bullous lesions. Selected patients have been treated with oral prednisone $(80$ $\mathrm{mg} /$ day); after twelve months of follow-up care the vegetating lesions disappeared completely, leaving hyperpigmentation. Rapid recurrence of lesions has also been observed when corticosteroids were discontinued; reinstitution of this therapy was followed by their regression.

As noted, the current literature highlights some differences between pemphigus vegetans of Hallopeau and pemphigus vegetans of Neumann. The differences between the two subsets center on their clinical presentation and course. Patients with the Hallopeau type often have a relatively benign disease requiring lower doses of systemic corticosteroids, and usually have a prolonged remission. Patients with the Neumann type have a course similar to pemphigus vulgaris; they need higher doses of systemic corticosteroids, and often have relapses and remissions. The histologic findings in the vegetating lesions are similar in both types [68-76]. The immunopathologic features of both types are indistinguishable, and similar to pemphigus vulgaris.

H\&E staining usually confirms acantholysis, papillomatosis, a few dysplastic keratinocytes and intraepidermal clefting with luminal acantholytic cells; in addition, neutrophils and eosinophils are often found in the epidermis. A dermal perivascular, mixed inflammatory cell infiltrate of eosinophils, plasma cells, lymphocytes, and histiocytes is often confirmed. DIF studies classically reveals deposits of $\operatorname{IgG}$ and $\mathrm{C} 3$ in the intercellular spaces of the epidermis, and IIF reveals circulating anti-epithelial IgG antibodies. The skin lesions classically completely clear following treatment with systemic corticosteroids and azathioprine. Some authors have also reported the presence of intercellular deposits of $\operatorname{IgA}$ or $\operatorname{IgM}$ $[77,78]$. Other clinical differential diagnoses are plaques of tuberculosis, deep fungal infections, skin carcinomas or tertiary syphilis.

\section{Pemphigus foliaceus (PF)}

The clinical features of PF were originally described by Dr Pierre Louis Alphée Cazenave in 1844, as a disease producing superficial cutaneous blisters and erosions. Dr. Cazanave described this non-endemic disease that occurs worldwide, with a low incidence [79]. PF is a rare skin disease, highlighted by the formation of flaccid bullae which then rupture, resulting in an inflamed, excoriated and fissured skin surface. It was originally thought that this disease does not affect the mucosae, but microscopic and immunopathological investigations have indeed demonstrated mucosal changes. PF is caused by autoantibodies directed against cell surface antigens on keratinocytes; these cells then lose their cellular adhesion properties, and separate from one another to form vesicles and bullae within the epidermis. Differences in the particular antigens targeted by the antibodies, and the distribution of these antigens in the different regions of the body and in differential layers of the epidermis then result in variable clinical manifestations of the disease. PF is diagnosed based on its clinical manifestations (flaccid blisters and erosions on skin), histologic findings (epidermal acantholysis), and immunologic abnormalities (circulating and tissue-fixed antibodies against keratinocytic cell surface antigens) [80-87]. Clinical PF lesions predominate in seborrheic areas (e.g, head, middle chest and umbilicus). The more common clinical lesions of PF are erythematous, confluent erosions with greasy crusts and peripheral collarette scales. The histopathology of early pemphigus foliaceus lesions demonstrates early vacuoles in the upper epidermal spinous and granular cell layers. Coalescence of these vacuoles results in the formation of acantholytic focio, which then progress to blister formation. Occasionally, epidermal lyperplasia is noted. Eroded lesions lacking the epidermal upper layers are commonly seen beause the blisters are so delicate that they rupture, either as a consequence of the skin biopsy itself or due to other mild trauma. Acantholytic keratinocytes are also frequently seen. A superficial dermal, perivascular and interstitial infiltrate of lymphocytes, eosinophils and lymphohisticyts is also commonly noted. Epidermal spongiosis and papillary dermal edema are often seen. In rare cases, neutrophilic spongiosis can be seen. An epidermal serum scale crust is often visualized. Similar to PV, the clinical and histologic features are not sufficient to make a certain diagnosis of PF. It is thus necessary to perform DIF and/or IIF, and/or ELISA testing to Dsg1/Dsg3. DIF classically confirms intercellular staining between epidermal keratynocytes (ICS), with deposits of IgG(mainly IgG4) and complement/C3; however, additional studies are confirming that as in PV, the immunoglobulins and complement deposits may be more polyclonal than previously believed. Since the blisters are superficial and easy to rupture, sporadic clinical lesions are similar of those seen in endemic pemphigus foliaceus (EPF) [45]. PF affects equally both sexes, and commonly presents in the fourth and fifth decades; desmoglein 1 (Dsg1) has been confirmed as one of the primary disease antigens; however, desmoplakin, periplakin and envoplakin have been also confirmed as disease antigens. PF may be exacerbated by sunlight and other ultraviolet radiation exposure, as described for PV $[88,89]$. Another immunologic phenomenon that has been described is antigen switching between PV and PF; however, many of these reports have not been confirmed. Burns should to be considered in the clinical differential diagnosis of PF; burns may further produce an immunologic epidermal intercellular staining between keratinocytes(ICS) [90]. Desmoglein 1 is also a major autoantigen in cases of $\mathrm{PH}$, suggesting that cases of both pemphigus erythematosus and pemphigus herpetiformis may be clinical variants of PF. The mechanism of induction of acantholysis by autoantibodies may involve phosphorylation of intracellular proteins associated with desmosomes. Complement activation does not appear to play a pathogenic role in PV. Finally, PF seems to have multiple variants: 1). Senear-Usher, or seborrheic; 2) Cazanave, or sporadic; and 3) endemic pemphigus foliaceus (EPF). Some authorities have also considered adding 4) pemphigus herpetiformis as a subvariant (Fig. 2).

\section{Endemic pemphigus foliaceus (EPF)}

In Brazil, this disorder was historically called fogo selvagem (FS), which in Portuguese means "wild fire". Later, Beutner, et. al., demonstrated that patients with PF exhibit anti-epidermal autoantibodies, which may be detected by DIF as well as IIF [19]. In PF, the most common immune response is directed against Dsg1 [91]. The predominant pathogenically relevant autoantibodies belong to the $\operatorname{IgG}$ subclass, and are more specifically IgG4 antibodies [80-110]. 

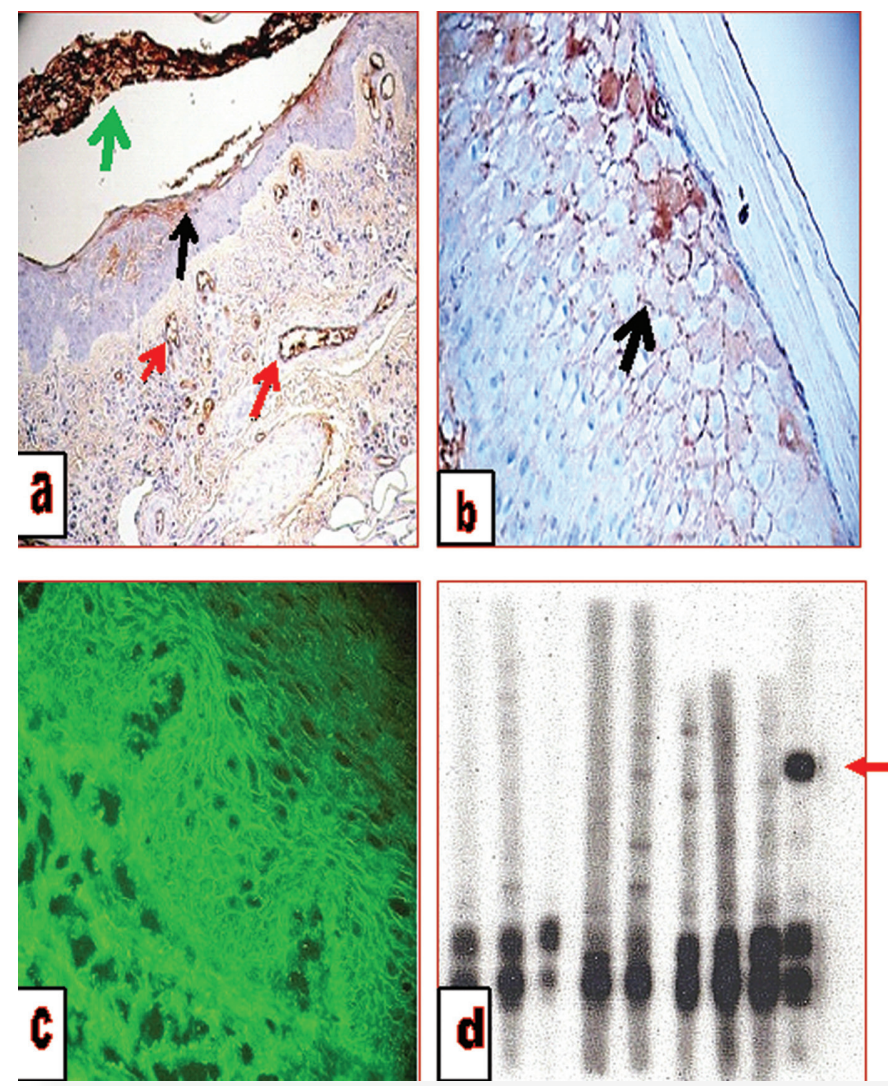

Figure 2. A typical reporting diagram of positivity for pemphigus foliaceus autoantigens in different groups and controls. a. A case of PF, using immunohistochemical staining (IHC) and Complement/C3c antibodies; shows suprabasilar staining (brown staining; black arrow), as well as deposits around the upper dermal blood vessels (brown staining; red arrow) and in subcorneal areas (brown staining;green arrow). b. A case of PF, with positive IHC using anti-human IgG antibodies; note the epidermal ICS(brown staining; black arrow). c. A case of PV, and DIF using monkey esophagus substrate. Note the typical ICS staining with FITC conjugated IgG antibodies (green staining; white arrow). d. A representative example of a Western immunoblot, using bovine snout tissue as the antigen source. The red arrow highlights positive staining to a $160 \mathrm{kDa}$ band, representing Dsg1.

Studies conducted in Brazil with FS patients have shown that serum titers of disease specific antibodies correlate well with clinical disease extent and activity. Interestingly, healthy relatives of FS patients may exhibit the presence of similar autoantibodies that seem to be non-pathogenic [80-110]. EPF has been described in other countries of South and central America, and may occur in high frequencies in families. For an extensive, recent review of EPF, please note references 94, 95 and 111. EPF has also been also described in Tunisia; however, this variant more closely resembles clinical pemphigus herpetiformis and affects predominantly young females with primary autoantibodies to Dsg1 [107-92]. In Colombia, both the fogo selvagem and El Bagre-EPF variants exist; the latter resembles Senear-Usher syndrome with systemic compromise and multiple autoantigens including desmogleins 1 and 3, desmoplakins, envoplakins, periplakins and additional, uncharacterized antigens [94$97,99,101,112,113]$. Some epidemiologic evidence suggests that EPF may be precipitated by environmental factors, including sunlight, other ultraviolet radiation, bed bugs, Trypanosoma cruzi, mercury, sand flies and others [89-110]. Some human leukocyte antigens (HLAs) have also been associated with presentation of this disease. Compared to PV, EPF is a more benign disease and can usually be treated with less aggressive therapy; however, in our experience, the generalized cases may be difficult to treat and result in high morbidity and mortality [94-97,99,101,112,113].

Antimalarials such as hydroxychloroquine $(200 \mathrm{mg} / \mathrm{d})$ may be useful as steroid-sparing agents in EPF. Finally, in patients with EPF, exposure to UVB may induce acantholysis in uninvolved skin. Epidermal exposure to UV light may enhance autoantibody epidermal binding and preferential neutrophil adhesion, which can contribute to acantholysis. The diagnostic workup for PF and EPF is similar to that described for PV.

\section{Senear Usher syndrome (SUS), also known as pemphigus} erythematosus.

SUS represents a variant of PF, with some features of systemic lupus erythematosus present simultaneously in the same patient. It was originally described by Senear and Usher in 1926 [114]. Generally, SUS is characterizated by deposition of immunoglobulins (mainly $\mathrm{IgG}$ ) and complement in the intercellular spaces of epidermal keratynocytes; similar staining is noted in patches along the BMZ. Dsg1 has been shown as the primary autoantigen. SUS autoantibodies have also been noted against deoxiribonucleic acid (DNA) in about one third of the patients. SUS is rare; as in PF, the majority of the lesions are in seborrheic areas. SUS usually develops insidiously with erythematous, scaly, crusted plaques in a butterfly distribution over the nose and malar areas. It may also involve the scalp, pectoral, and interscapular regions. SUS lesions may persist for long periods; as in PF, sunlight sometimes adversely affects its course [114-120]. SUS is very rare in children. SUS is occasionally found in association with other autoimmune diseases, especially myasthenia gravis with an accompanying thymoma. The SUS diagnostic workup and treatment is similar to $\mathrm{PF}$.

\section{Pemphigus herpetiformis (PH)/pemphigus serpiginosus of Hebra.}

$\mathrm{PH}$ represents a variant of PF that presents with circiform and/ or herpetiform clinical lesions, and histologic subepidermal/ suprabasal blisters with strong eosinophilia. The first cases were reported by Drs. Hebra, Unna, Brocq and Leredde [120]. At the time of the original clinical and histopathologic descriptions, DIF was not available for workup. Later, Jablonska, et. al. were able better characterize immunologic features of this disease [122]. Further, over time more cases were documented, and some authors were able to follow these patients for long periods. Dsg1 was eventually confirmed as the disease autoantigen [123126]. Other authors reported additional antigens; however, due to the low number of cases available for study, some controversy exists in precisely correlating the clinical, histopathologic, immunologic and molecular diagnostic findings in this disorder [127]. In our combined experience, we have followed patients with endemic pemphigus and noted that they can drift over time form one clinical presentation to another, and also exhibit immunologic drift. The early Brazilian researchers had the opportunity to closely follow fogo selvagem patients, and had also described the clinical drift phenomenon. 
In PH, itching is common; some initial histopathologic changes we have noted in our PH patients include eczema-like epidermal spongiosis with eosinophilia, and possible subepidermal and/ or subcorneal bullae. DIF in our cases showed consistent intercellular IgG staining; IIF on monkey esophagus substrate confirmed this finding in several cases. About half of our patients responded to therapy with sulfones and prednisone, and only one patient responded to sulfones alone. Half of our patients required either combined therapy with prednisone and cyclophosphamide, or with higher doses of prednisone. In our consecutive relapse patients, nine patients retained the pattern of pemphigus herpetiformis; in the others, lesions mostly resembled pemphigus foliaceus. Our most common clinical differential diagnoses included diseases with grouped vesicles such as dyshidrosis, nummular dermatitis, herpes simplex, and herpes zoster; diseases with grouped vesicobullae such as dermatitis herpetiformis, herpes gestationis, subacute lupus erythematosus(bullous variant); and diseases with grouped pustules such as pustular psoriasis, dermatitis continua of Hallopeau, and impetigo herpetiformis.

\section{IgA pemphigus/subcorneal pustular dermatosis (Sneddon- Wilkinson disease).}

The subcorneal pustular dermatosis of Sneddon and Wilkinson belongs to the heterogeneous group of neutrophilic dermatoses. Sneddon Wilkinson disease is a chronic, sterile pustular eruption and first described by Sneddon and Wilkinson in 1956 [128]. The disease represents a unique disorder, and is characterized by a superficial pustular eruption. The disease pustules are flaccid and aseptic. They develop predominantly on the trunk, groin, axillae and submammary areas. Sneddon Wilkinson disease is often clinically chronic and benign. However, some scattered reports had shown associations with other conditions, including lymphoproliferative and myeloproliferative diseases (monoclonal gammopathies, such as IgA paraproteinemias) and other malignancies. Dapsone is the treatment of choice to control the skin manifestations. The nosologic value of Sneddon Wilkinson disease is still debated, especially vis-a-vis $\operatorname{IgA}$ pemphigus, which often is successfully treated with the same dosages of dapsone. Most patients respond well to dapsone, although in rare instances they require etretinate.

Several studies studied vesiculobullous lesions that resembled pemphigus foliaceus clinically and histopathologically; however, some displayed intercellular IgA, but not IgG, in the epidermis by direct immunofluorescence. Similar histologic and immunofluorescence findings have been reported in eight other cases. In our cases, no circulating $\operatorname{IgA}$ or $\mathrm{IgG}$ intercellular antibodies could be detected; in four of the eight previously noted cases, IgA antibodies demonstrated epidermal intercellular staining, similar to a pemphigus pattern [128-148]. A different classification would suggest that the IgA pemphigus cases reported to date fall into one of two groups; specifically, 1) an IgA pemphigus foliaceus group, and 2) an IgA pemphigus of intraepidermal neutrophilic type (ie, Sneddon-Wilkinson disease), which seems to be clinically less common. In our experience, we have encountered three cases of intercellular IgA dermatosis. Somehow, it seems that the world has often merged IgA pemphigus and subcorneal pustular dermatosis (Sneddon-Wilkinson disease) and many confusing reports group them together. Notably, before immunopathologic studies were available, dermatologists and dermatopathologists identified many of these cases as Sneddon-Wilkinson disease. Later, when the immunopathologic studies become more available it seems that many authors mixed both diseases [149-153]. Some cases of PF have autoantibodies to IgA, in addition to IgG, or IgM (personal experiences). Additionally, a few cases of PF have IgA ICS, but without characteristic neutrophilic features of Sneddon-Wilkinson disease. Further, some autoantigens such as desmocollins and Dsg1 have been named as putative autoantigens by the same groups of authors. Clearly, many of these cases differ from classic Sneddon-Wilkinson disease.

Indeed, we recently reported a typical case of SneddonWilkinson disease, in which biopsies for H\&E, DIF and immunohistochemistry (IHC) analysis were performed. The H\&E staining demonstrated typical features of SneddonWilkinson disease, including some damage to dermal pilosebaceous units subjacent to the subcorneal blistering process. By DIF, FITC conjugated IgE, IgA and fibrinogen were observed in an epidermal pericytoplasmic and perinuclear pattern, with several additional foci within the epidermal stratum corneum $(++)$. Other findings included $\operatorname{IgM}(+$, intercellular epidermal stratum spinosum); $\operatorname{IgD}(+/-$, focal BMZ cytoid bodies; complement/C1q (-); complement/C3 (+, roof of subcorneal pustules); albumin ( + , intercellular epidermal stratum spinosum); and fibrinogen ( ++ , focally within papillary dermal tip areas, focally within the superficial corneal layer, and surrounding some upper and intermediate dermal blood vessels). The blister lumens were positive for IgG, IgA, IgM, $\operatorname{IgE}$ and fibrinogen. DIF also revealed strong deposits of the immunoreactants $\operatorname{IgG}, \operatorname{IgM}$, fibrinogen and complement/C3, present in a shaggy pattern within the subcorneal disease areas; in focal, areas of the basement membrane junction and in focal pericytoplasmic areas of epidermal keratinocytes. IHC revealed strong positivity to HLA-DPDQDR, mast cell tryptase, CD68, and ZAP-70 in the subcorneal luminal inflammatory infiltrate, and surrounding dermal blood vessels. Myeloperoxidase staining was also positive in these areas [154] (Tabl. II).

\section{Drug induced pemphigus}

Drugs and radiotherapy are important causes of pemphigus. The diagnosis of drug-induced pemphigus may be difficult. Patients have often been exposed to multiple drugs, and some drugs may have a prolonged latency period between exposure and the onset of disease. Some of the most frequently associated medications include D-penicillamine, captopril, clavulinic acid, amoxicillin, imiquimoid, lisinopril and rifampin [155161]. With patients taking multiple medications, drug-drug interactions may represent a triggering factor. Food supplements, non-prescription medications and topical medications should always be considered. Patients who suffer drug-induced pemphigus usually present with a clinical picture of $\mathrm{PF}$, and less frequently PV [155-162]. The DIF and IIF usually show deposits of predominantly IgG ICS; some reports of antigenicity against epidermal keratinocyte cytoplasms exist. The disease is often transient and resolves shortly after the drug has been discontinued, especially in those patients that lack evidence of circulating antibodies. Skin biopsies of drug-induced and idiopathic pemphigus were reviewed by five dermatologists, with no clinical data available about the patients [158]. The sections were assessed for the presence of epidermal spongiosis with eosinophils, vacuolar degeneration, acantholysis and cleavage level. Using the criteria, the reviewers were unable to correctly identify a clinical case of drug-induced pemphigus. 


\begin{tabular}{|c|c|c|c|c|}
\hline Disease & Variants & DIF & Target antigen/s & Differential diagnoses \\
\hline Pemphigus foliaceus & Cazanave's, Senear-Usher and EPF. & $\begin{array}{l}\text { ICS with IgG, IgM, } \\
\text { IgG, kappa, lambda and } \\
\text { Complement/C3 and } \\
\text { C1q, mainly in the upper } \\
\text { epidermis. }\end{array}$ & $\begin{array}{l}\text { Dsg1, Dsg3, } \\
\text { envoplakin, } \\
\text { periplakin and } \\
\text { desmoplakins. }\end{array}$ & $\begin{array}{l}\text { Impetigo, dermatophytes, burns, } \\
\text { acantholytic actinic keratosis, } \\
\text { Staphylococcal scalded skin } \\
\text { syndrome/SSSS, acute generalized } \\
\text { exantemous pustulosis/AGEP. }\end{array}$ \\
\hline Pemphigus vulgaris & $\begin{array}{l}\text { Hallopeau, Neumann, and } \\
\text { pyostomatitis vegetans with or } \\
\text { without bowel involvement. }\end{array}$ & $\begin{array}{l}\text { IgG and Complement/C3 } \\
\text { ICS, and fibrinogen } \\
\text { mainly in basilar } \\
\text { epidermis. }\end{array}$ & $\begin{array}{l}\text { Dsg } 1 \text { and 3, DSC1, } \\
\text { DSC3, ATP2C1, } \\
\text { acetylcholine. }\end{array}$ & $\begin{array}{l}\text { Viral infections, Hailey- Hailey, } \\
\text { Grover's, friction, Darier's, disease, } \\
\text { burns, aphtous stomatitis, } \\
\text { gingivostomatitis, erythema } \\
\text { multiforme, erosive lichen planus, } \\
\text { blastomycosis, candidiasis, } \\
\text { botroymcosis, axillary granular } \\
\text { parakeratosis. }\end{array}$ \\
\hline $\begin{array}{l}\text { Paraneoplastic } \\
\text { pemphigus }\end{array}$ & Unknown. & $\begin{array}{l}\text { Mainly IgG and } \\
\text { Complement/C3 ICS; } \\
\text { also BMZ. }\end{array}$ & $\begin{array}{l}\text { Envoplakins, } \\
\text { periplakins, Dsg1, } \\
\text { Dsg3, BP180 and } \\
\text { 230, desmoplakins } \\
\text { plectins, } \alpha 2- \\
\text { macroglobulin-like } \\
\text { protein } 1 .\end{array}$ & $\begin{array}{l}\text { Erythema multiforme, erosive lichen } \\
\text { planus, herpetic lesions, staphyloccal } \\
\text { scalded skin syndrome/SSSS. }\end{array}$ \\
\hline Drug-induced pemphigus & $\begin{array}{l}\text { Pemphigus vulgaris and pemphigus } \\
\text { foliaceus-like. }\end{array}$ & $\begin{array}{l}\text { IgG and Complement } / \mathrm{C} 3 \\
\text { ICS, mainly in the upper } \\
\text { epidermis. }\end{array}$ & $\begin{array}{l}\text { Dsg1, Dsg3 and } \\
\text { other } \\
\text { uncharacterized } \\
\text { antigens. }\end{array}$ & $\begin{array}{l}\text { Halogenoderma, erythema } \\
\text { multiforme,Stevens-Johnson. }\end{array}$ \\
\hline IgA Pemphigus & Subcorneal and other. & $\begin{array}{l}\text { IgA (ICS and/or } \\
\text { cytoplasmic), IgM and } \\
\text { fibrinogen. }\end{array}$ & $\begin{array}{l}\text { Dsg } 3 \text { and } \\
\text { desmocollins. }\end{array}$ & $\begin{array}{l}\text { Infantile acropustulosis (subcorneal), } \\
\text { erythem toxico neonatorum, miliaria. }\end{array}$ \\
\hline IgE Pemphigus & Unknown. & ICS IgE. & Dsg1 and Dsg3. & Any of the above \\
\hline
\end{tabular}

Thus, it is advisable to consider drug etiology in every case of newly diagnosed pemphigus, as histologic features cannot reliably differentiate between drug-associated and idiopathic disease [158]. Therapy consists of cessation of the target medication.

\section{Intercellular IgE pemphigus ("IgE pemphigus")}

$\mathrm{IgG} 4$ and $\mathrm{IgE}$ are present in most autoimmune skin diseases. However, it is not clear that an IgG4 or IgE ICS pemphigus nosologically exists [163-170]. In many conditions such as PV, PF, EPF and El-Bagre-EPF, IgE ICS autoantibodies have been documented. It is further not presently clear if the $\operatorname{IgE}$ antibodies are elevated as result of isotype switching, and/or are possibly recognizing specific antigen sites. Notably, increased serum IgE levels are occasionally found in patients with pemphigus. The IgE elevation is often simultaneously present with lesional deposition of eosinophils. In fogo selvagem, antiDsg1 antibodies have been associated with disease onest; the same is true with Dsg3-specific IgE and IgG4 autoantibodies in PV [163-170]. Thus, more cases of IgE pemphigus are needed to adequately investigate these questions.

\section{Paraneoplastic pemphigus (PNP)}

PNP is a recently described blistering disorder that arises exclusively in the context of a neoplasma (most commonly a nonHodgkin's lymphoma) has polymorphous skin lesions. These lesions display clinical and histologic features of both erythema multiforme and PV. Other neoplasms associated with PNP include cases of CD20-positive follicular lymphomas, chronic lymphocytic leukemia, thymoma, hepatocellular carcinoma, malignant fibrous histiocytoma, inflammatory myofibroblastic tumor, follicular dendritic cell sarcoma, Waldenström's macroglobulinemia, B-cell lymphocytic leukemia/lymphoma, uterine carcinoma and Castleman's disease. When associated with a malignancy, the course of the disease is usually fatal. If the associated neoplasm is benign and it is removed, the PNP lesions may respond to treatment with corticosteroids and resolve completely. Rarely, PNP lesions may resemble $\mathrm{BP}$, or present as a lichenoid tissue reaction. In addition to the polymorphous skin lesions, patients may develop prominent, painful mucous membrane ulcerations. Involvement of internal organs, such as pulmonary and gastrointestinal tracts, may also be observed. Histologically, skin and mucosal lesions typically present intraepithelial cleavages with suprabasal acantholysis and interface changes featuring necrotic and apoptotic keratinocytes. DIF studies reveal intraepidermal and/or BMZ deposition of IgG and/or C3 complement component, whereas by IIF PNP sera contain autoantibodies binding to stratified, complex and simple epithelia, as well as to the myocardium of the heart. Gallbladder positivity may also be noted in PNP [171-186]. Sera of patients with PNP will immunoprecipitate Dsg1, Dsg3, desmoplakin I (250 kD), bullous pemphigoid antigen I (230 kd), desmoplakin II $(210 \mathrm{kD})$, envoplakin $(210 \mathrm{kD})$, periplakin $(190 \mathrm{kD})$, plectin $(500 \mathrm{kD})$ and a $170-\mathrm{kD}$ protein, that has been reported as alpha-2-macroglobulin-likeprotein 1, a broad range protease inhibitor expressed in stratified epithelia and other tissue damaged in PNP. PNP is characterized by the presence of autoantibodies directed against components of the ICS, as well as against the BMZ [171-180]. In one study, patients with PNP presented initially with isolated oral erosions that were undistinguishable from those seen in PV patients, and $27 \%$ had histologic findings of only suprabasal acantholysis. The association with a lymphoproliferative disorder, diagnostic IIF labeling of rat bladder, and immunoblotting recognition of envoplakin and/or periplakin represented sensitive and specific features leading to the diagnosis of PNP. 
Recently, it has also been reported that alemtuzumab is effective against severe chronic lymphocytic leukemia-associated PNP [187]. In these patients, the presence of blisters with histologic and immunofluorescence evidence of pemphigus have been demonstrated [188,189]. Neonatal pemphigus is caused by transfer of maternal IgG autoantibodies against Dsg3 or Dsg1 to the neonate through the placenta when the mother is affected by one of the pertinent diseases. Neonatal pemphigus is clinically characterized by transient, flaccid blisters and erosions on the skin, and rarely on the mucous membranes $[188,189]$. Neonatal pemphigus vulgaris has never been reported to persist beyond the neonatal period and progress to adult disease. Usually neonatal pemphigus lesions are self limiting, and resolve within two weeks. Neonatal pemphigus needs to be differentiated from the "pemphigus neonatorum" of the distant past medical literature, referring to babies with Staphylococcal skin disease [200].

\section{Pemphigus in animals}

Animals, especially dogs, cats and horses can develop PF, PV, and drug induced pemphigus [201-204].

\section{Treatment}

Prednisone is the most common therapy for autoinmune cutaneous blistering diseases, and the initial dose is based on clinical stage of the patient. Generally, $1-2 \mathrm{mg} / \mathrm{kg} / \mathrm{day}$ are utilizad, supplemented with broad range antiparasitic medicines, calcium supplements, topical corticosteroid cream and sun protection. Sometimes, antibiotic prophylaxis to prevent wound infection is recommended. Several immunosuppressive agents including cyclophosphamide, azathioprine, methotrexate, cyclosporine and gold have been utilized in therapy; for severe cases, plasmapheresis, photopheresis and high-dose intravenous gammmaglobulins have also been used [204-220]. Cloroquine is also used as a coadjuvant. One initial large study on the treatment of 84 patients with PV was conducted between 1961 and 1982 by Dr Walter Lever [204]. Over time, the study showed that 47 of the 84 patients were free of lesions, and not receiving treatment. Twenty-two of the patients had been without lesions and treatment for more than five years. There had been no disease- or treatment-related fatalities since 1976. Since the Lever study, other therapeutic modalities had been added; these include combined treatment with small, alternating day doses of prednisone, plus a daily dose of a different immunosuppressant agent (usually azathioprine). In mild, relatively stable cases, the combined form of treatment may be given initially. Thus, in addition to prednisone monotherapy, prednisone combined with other immunosupressors ("adjuvants"), ie, azathioprine (2 mg/ $\mathrm{kg} / \mathrm{d})$, cyclosporine $(2.5-3 \mathrm{mg} / \mathrm{kg} / \mathrm{d})$, cyclophosphamide (1.1$1.5 \mathrm{mg} / \mathrm{kg} / \mathrm{d})$, mycophenolate mofetil (2 g/d), mycophenolate sodium have show good results in pemphigus treatment [204220]. Many combinations of prednisone and adjuvants have been utilized. In many cases, superinfections represent the most dangerous complications of the therapy. Thus, if the patient needs to be hospitalized, testing for tuberculosis and parasitic diseases should be conducted before any treatment. If strong immunosuppression will be given, the patient needs to be hospitalized for this reason alone. In these cases, admission tests such as EKG, chest radiography, kidney and liver electrolytes and a $\mathrm{CBC}$ need to be performed. If the admitting physician is suspicious of any superinfection on the skin, cultures need to be taken before initiation of therapy. Biopsies should be taken for H\&E studies and for DIF studies in Michel's medium. In addition, serum for IIF, immunoblotting and ELISA testing should be obtained. The patient needs to be bathing if possible, cleaning the flexural areas; the mouth needs to be cleaned and colleagues such as ENT, oral surgery, urology and others may be consulted to treat the patients. If the patients have severe oral lesions, a nutritionist should be consulted for appropriate protein control in the diet. Additional therapies such as high-dose intravenous immunoglobulin, rituximab and immunoadsorption are used for refractory patients. Some of these therapies may require 4 weeks to be effective.

Appropriate nursing care is also important with immunosupression therapy. The application of topical steroids over a wide area is a safe and effective treatment for thesegroup of diseases, but again the physicians and nurses should monitor the amount of skin that is affected because these patients can become toxic easily. Finally, the therapy of pemphigus with oral corticosteroids has well documented side effects, including systemic infections, high blood sugar, loss of bone density, caries, osteoporosis, thromboses and gastrointestinal ulcers.

\section{REFERENCES}

1. Civatte A, Tzanck A, Dobkevitch S: Ann Dermatol Syphiligr (Paris). 1946;6:486.

2. Teanok A, Aron-Brunetire R: Arch Bel q Derm Syph. 1949;5:276.

3. Lever WF: Pemphigus and pemphigoid: a review of the advances made since 1964. J Am Acad Dermatol. 1979;1:1-31.

4. Lever WF: Pemphigus and pemphigoid. Charles C. Thomas, Springfield, 1965.

5. Robin AC, Brown G: Lecture notes on Dermatology. Blackwell Scientific Ltd, England, 7ed, Lecture notes series, 1996.

6. Moss C: Dermatology and the new genetics (eds) Blackwell Science, England Ltd, 1995

7. Anderson TF, Voorhees JJ: Thiers BH, Dobson RL (eds): Pathogenesis of skin disease. New York, Churchill Livingstone, 1996.

8. Hertl M, Niedermeier A, Borradori L: Autoimmune bullous skin disorders. Ther Umsch. 2010;67:465-82.

9. Beutner EH, Jordon RE: Demonstration of skin antibodies in sera of pemphigus vulgaris patients by indirect immunofluorescent staining. Proc Soc Exp Biol Med. 1964;117:505-10.

10. Beutner EH, Lever WF, Witebsky E, Jordon R, Chertock B: Autoantibodies in pemphigus vulgaris: response to an intercellular substance of epidermis. JAMA. 1965;192:682-8.

11. Jordon RE, Beutner EH, Witebsky E, Blumental G, Hale WL, Lever WF: Basement zone antibodies in bullous pemphigoid. JAMA. 1967;29:751-6.

12. Lever WF: Differential diagnosis of pemphigus vulgaris, bullous pemphigoid and dermatitis herpetiformis. Med Klin. 1967;62:11736.

13. Lever WF: Medicine (Baltimore). Pemphigus. 1953;32:1-123.

14. Wilgram GF, Caufield JB, Lever WF: Electron microscopic studies in skin diseases with acantholysis (pemphigus vulgaris, pemphigus familiaris benignus chronicus, darier's disease. Dermatol Wochenschr. 1964;147:281-92.

15. Wilgram GF, Caulfield JB, Lever WF: An electron microscopic study of acantholysis in pemphigus vulgaris. J Invest Dermatol. 1961;36:373-82.

16. Chorzelski TP, Von Weiss JF, Lever WF: Clinical significance of autoantibodies in pemphigus. Arch Dermatol. 1966;93:570-6.

17. Hashimoto K, Lever WF: An ultrastructural study of cell junctions in pemphigus vulgaris. Arch Dermatol. 1970;101:287-98. 
18. Hashimoto K, Lever WF: An electron microscopic study on pemphigus vulgaris of the mouth and the skin with special reference to the intercellular cement. J Invest Dermatol. 1967;48:540-52.

19. Beutner EH, Prigenzi LS, Hale W, Leme Cde A, Bier OG: Immunofluorescent studies of autoantibodies to intercellular areas of epithelia in Brazilian pemphigus foliaceus. Proc Soc Exp Biol Med. 1968;127:81-6.

20. Chorzelski TP, Jablonska S, Jarzabek-Chorzelska M, Beutner EH, Nisengard RJ, Kumar V, et al: Reliability of indirect immunofluorescence testing. Arch Dermatol. 1980;116:1228-9.

21. Jordon RE, Sams WM Jr, Beutner EH: Complement immunofluorescent staining in bullous pemphigoid. J Lab Clin Med. 1969;74:548-56

22. Camisa C, Helm TN: Paraneoplastic pemphigus is a distinct neoplasia-induced autoimmune disease. Arch Dermatol. 1993;129:883-6.

23. Amagai M, Klaus-Kovtun V, Stanley JR: Autoantibodies against a novel epithelial cadherin in pemphigus vulgaris, a disease of cell adhesion. Cell. 1991;67:869-77.

24. Kárpáti S, Amagai M, Prussick R, Stanley JR: Pemphigus vulgaris antigen is a desmosomal desmoglein. Dermatology. 1994;189 Suppl 1:24-6.

25. Kárpáti S, Amagai M, Prussick R, Cehrs K, Stanley JR: Pemphigus vulgaris antigen, a desmoglein type of cadherin, is localized within keratinocyte desmosomes. J Cell Biol. 1993;122:409-15.

26. Emery DJ, Diaz LA, Fairley JA. Lopez A, Taylor AF, Guidice GJ Pemphigus foliaceus and pemphigus vulgaris autoantibodies react with the extracellular domain of desmoglein 1. J Invest Dermatol. 1995; 104:323-8.

27. Stanley JR, Koulu L, Thivolet C: Distiction between epidermal antigens binding pemphigus vulgaris and pemphigus foliaceus utoantibodies. J Clin Invest. 1984;74:313-20.

28. Amagai M, Hashimoto T, Shimizu N: Absorption of pathogenic autoantibodies by the extracellular domain of pemphigus vulgaris antigen (Dsg3) produced by baculovirus. J Clin Invest. 1994;94:5967.

29. Stanley JR, Yaar M, Hawley-Nelson P, and Katz SI: Pemphigus antibodies identify a cell surface glycoprotein synthesized by human and mouse keratinocytes. J Clin Invest 1982; 70:281-8.

30. Hashimoto T, Ogawa MM, Konohana A, and Nishikawa T: Detection of pemphigus vulgaris and pemphigus foliaceus antigens by immunoblot analysis using different antigen sources. J Invest Dermatol. 1990; 94:327-31.

31. Koch PJ, Walsh MJ, Schmelz M, Goldschmidt MD, Zimbelmann $\mathrm{R}$, et al: Identification of desmoglein, a constitutive desmosomal glycoprotein, as a member of the cadherin family of cell adhesion molecules. Eur J Cell Biol. 1990; 53:1-12.

32. Mimouni D, Foedinger D, Kouba DJ, Orlow SJ, Rappersberger $\mathrm{K}$, Sciubba JJ, et al: Mucosal dominant pemphigus vulgaris with antidesmoplakin autoantibodies. J Am Acad Dermatol. 2004;51:62-7.

33. Olivry T, Alhaidari Z, Ghohestani RF: Anti-plakin and desmoglein autoantibodies in a dog with pemphigus vulgaris. Vet Pathol. 2000;37:496-9.

34. Kalantari-Dehaghi M, Anhalt GJ, Camilleri MJ, Chernyavsky AI, Chun S, Felgner PL, et al: Pemphigus vulgaris autoantibody profiling by proteomic technique. PLoS One. 2013;8:e57587.

35. Kalantari-Dehaghi M, Molina DM, Farhadieh M, Morrow WJ, Liang X, Felgner PL, et al: New targets of pemphigus vulgaris antibodies identified by protein array technology. Exp Dermatol. 2011;20:154-6.

36. Pradeep AR, Manojkumar ST, Arjun R: Pemphigus vulgaris with significant periodontal findings: a case report. J Calif Dent Assoc. 2010;38:343-6.

37. Mignogna MD, Lo Muzio L, Bucci E: Clinical features of gingival pemphigus vulgaris. J Clin Periodontol. 2001;28:489-93.

38. Samy LL, Girgis IH, Wasef SA: Pharyngeal and laryngeal pemphigus. J Laryngol Otol. 1968;82:111-21.
39. Durovic E, Sak M: Contribution to the incidence of pemphigus vulgaris and its manifestations on the mouth mucosa.Cesk Otolaryngol. 1969;18:35-8.

40. Tsiriopoulos I, Kiorpelidou D, Gaitanis G, Sofikitis N, Bassukas ID: Lower urinary tract involvement in patients with newly diagnosed autoimmune bullous dermatoses: an urethrocystoscopic study. Am J Med Sci. 2010;340:109-13.

41. Brackley R, Pagani JM: Conjunctival erosions associated with pemphigus vulgaris. Optom Vis Sci. 2011;88:1010-3.

42. Bianciotto C, Herreras Cantalapiedra JM, Alvarez MA, Méndez Díaz MC: Conjunctival blistering associated with pemphigus vulgaris: report of a case. Arch Soc Esp Oftalmol. 2005;80:365-8.

43. Epstein JH, Feigen GM, Epstein NN: Pemphigus vulgaris with lesions of the rectal mucosa. AMA Arch Derm. 1958;78:36-8.

44. Stone DD: Rectal lesions and toxic dilatation of the colon in a case of pemphigus vulgaris. Am J Dig Dis. 1971;16:163-6.

45. Lever WF, Schaumburg-Lever. Histopathology of the skin. 1975. Lippincott, Philadelphia.

46. Director W: Pemphigus vugaris; a clinicopathologic study. AMA Arch Derm Syphilol. 1952;65:155-69

47. Firooz A, Mazhar A, Ahmed AR: Prevalence of autoimmune diseases in the family members of patients with pemphigus vulgaris. J Am Acad Dermatol. 1994;31:434-7.

48. Ahmed AR, Wagner R, Khatri K, Notani G, Awdeh Z, Alper CA, et al: Major histocompatibility complex haplotypes and class II genes in non-Jewish patients with pemphigus vulgaris. Proc Natl Acad Sci U S A. 1991;88:5056-60.

49. Lombardi ML, Mercuro O, Ruocco V, Lo Schiavo A, Lombari $\mathrm{V}$, Guerrera V, et al.: Common human leukocyte antigen alleles in pemphigus vulgaris and pemphigus foliaceus Italian patients. J Invest Dermatol. 1999;113:107-10.

50. Reohr PB, Mangklabruks A, Janiga AM, DeGroot LJ, Benjasuratwong Y, Soltani K: Pemphigus vulgaris in siblings: HLADR4 and HLA-DQw3 and susceptibility to pemphigus. J Am Acad Dermatol.1992;27:189-93.

51. Slomov E, Loewenthal R, Goldberg I, Korostishevsky M, Brenner $\mathrm{S}$, Gazit E: Pemphigus vulgaris in Jewish patients is associated with HLA-A region genes: mapping by microsatellite markers. Hum Immunol. 2003;64:771-9.

52. Szafer F, Brautbar C, Tzfoni E, Frankel G, Sherman L, Cohen $\mathrm{I}$, et al: Detection of disease-specific restriction fragment length polymorphisms in pemphigus vulgaris linked to the DQw1 and DQw3 alleles of the HLA-D region. Proc Natl Acad Sci USA. 1987;84:6542-5

53. Gazit E, Slomov Y, Goldberg I, Brenner S, Loewenthal R: HLA-G is associated with pemphigus vulgaris in Jewish patients. Hum Immunol. 2004;65:39-46.

54. Koc CK, Sallakci N, Akman-Karakaş A, Alpsoy E, Yegin O: Human leukocyte antigens class I and class II in patients with pemphigus in southern Turkey. Int J Dermatol. 2013;52:53-8.

55. Bhanusali DG, Sachdev A, Rahmanian A, Gerlach JA, Tong JC, Seiffert-Sinha K, et al: HLA-E*0103X is associated with susceptibility to Pemphigus vulgaris. Exp Dermatol. 2013;22:10812.

56. Marzano AV, Tourlaki A, Merlo V, Spinelli D, Venegoni L, Crosti $\mathrm{C}$ : Herpes simplex virus infection and pemphigus. Int J Immunopathol Pharmacol. 2009;22:781-6.

57. Morell-Dubois S, Carpentier O, Cottencin O, Queyrel V, Hachulla E, Hatron PY, et al: Stressful life events and pemphigus.Dermatology. 2008;216:104-8.

58. Valikhani M, Kavusi S, Chams-Davatchi C, Daneshpazhooh M, Barzegari M, Ghiasi M, et al: Pemphigus and associated environmental factors: a case-control study. Clin Exp Dermatol. 2007;32:256-60.

59. Wohl Y, Brenner S: Pemphigus in Israel--an epidemiologic analysis of cases in search of risk factors. Isr Med Assoc J. 2003;5:410-2. 
60. Abréu Vélez AM, Yepes MM, Patiño PJ, Bollag WB, Montoya F: A cost-effective, sensitive and specific enzyme-linked immunosorbent assay useful for detecting a heterogeneous antibody population in sera from people suffering a new variant of endemic pemphigus. Arch Dermatol Res. 2004;295:434-41.

61. Ide A, Hashimoto T, Amagai M, Tanaka M, Nishikawa T: Detection of autoantibodies against bullous pemphigoid and pemphigus antigens by an enzyme-linked immunosorbent assay using the bacterial recombinant proteins. Exp Dermatol. 1995;4:1126.

62. Kamiya K, Aoyama Y, Shirafuji Y, Hamada T, Morizane S, Fujii $\mathrm{K}$, et al: Detection of antibodies against the non-calcium-dependent epitopes of desmoglein 3 in pemphigus vulgaris and their pathogenic significance. Br J Dermatol. 2012;167:252-61.

63. Kamiya K, Aoyama Y, Shirafuji Y, Hamada T, Morizane S, Fujii K, et al: A higher correlation of the antibody activities against the calcium-dependent epitopes of desmoglein 3 quantified by ethylenediaminetetraacetic acid-treated enzyme-linked immunosorbent assay with clinical disease activities of pemphigus vulgaris. J Dermatol Sci. 2013;70:190-5.

60. Grob PJ, Inderbitzin TM: Experimental production in rabbits of antiepithelial autoantibodies. J Invest Dermatol. 1967;49:637-41.

61. Beutner EH, Chorzelski TP, Jarzabek M, Wood GW, Leme Cde A, Bier O: Studies in immunodermatology. I. Passive induction of intraepidermal clefts in rabbits by transfer of sera from Brazilian Pemphigus foliaceus patients. Int Arch Allergy Appl Immunol. 1972;42:545-55.

62. Ablin RJ, Beutner EH: Precipitation of epithelia antigen(s) with pemphigus-like autoantibodies of rabbit and human pemphigus autoantibodies. Experientia. 1968;24:1055.

63. Wood GW, Beutner EH, Chorzelski TP: Studies in immunodermatology. II. Production of pemphigus-like lesions by intradermal injection of monkeys with Brazilian pemphigus foliaceus sera. Int Arch Allergy Appl Immunol. 1972;42:556-64.

64. Sabolinski ML, Beutner EH, Krasny S, Kumar V, Huang J, Chorzelski TP, et al: Substrate specificity of anti-epithelial antibodies of pemphigus vulgaris and pemphigus foliaceus sera in immunofluorescence tests on monkey and guinea pig esophagus sections. J Invest Dermatol. 1987;88:545-9.

65. Anhalt GJ, Labib R, Voorhees JJ, Beals TF, Diaz LA: Induction of pemphigus in neonatal mice by passive transfer of $\operatorname{IgG}$ from patients with the disease. N Engl J Med. 1982;306:1189-96.

66. Hata T, Nishifuji K, Shimoda K, Sasaki T, Yamada T, Nishikawa $\mathrm{T}$, et al: Transgenic rescue of desmoglein 3 null mice with desmoglein 1 to develop a syngeneic mouse model for pemphigus vulgaris. J Dermatol Sci. 2011;63:33-9.

67. Yokoyama T, Matsuda S, Takae Y, Wada N, Nishikawa T, Amagai $\mathrm{M}$, et al: Antigen-independent development of Foxp3+ regulatory $\mathrm{T}$ cells suppressing autoantibody production in experimental pemphigus vulgaris. Int Immunol. 2011;23:365-73.

68. Hallopeau: Pyodermitis vegetante. iHre Beziehungen zur dermatitis herpetiformis und dem pemphigus vegetants. Archiv F Derm U Syph. Bd XLIV 1898:289.

69. Hallopeau: Zweitc Mittheilung ueber „Pyodermite Vegetante.” (Suppurative Form der Ncumann'schen Krankheit. Archiv F Derm U Syph. Bd XLV, 1898:323.

70. Roeckl H: [On pyoderma vegetans hallopeau as a benign form of pemphigus vegetans Neumann with some remarks on pyostomatitis vegetans mccarthy]. Arch Klin Exp Dermatol. 1964;218:574-82.

71. Nelson CG, Apisarnthanarax P, Bean SF, Mullins JF: Pemphigus vegetans of Hallopeau: immunofluorescent studies. Arch Dermatol. 1977;113:942-5.

72. Leroy D, Lebrun J, Maillard V, Mandard JC, Deschamps P: Pemphigus vegetans, a clinical type of chronic pustular dermatitis of Hallopeau. Ann Dermatol Venereol. 1982;109:549-55.

73. Newman BA, Feldman F: Pemphigus vegetans: involution with cortisone therapy. AMA Arch Derm Syphilol. 1951;64:105.
74. Neumann HA, Faber WR: Pyodermite végétante of Hallopeau. Immunofluorescence studies performed in an early disease stage. Arch Dermatol. 1980;116:1169-71.

75. Brinkmeier T, Frosch PJ: Pyodermatitis-pyostomatitis vegetans: a clinical course of two decades with response to cyclosporine and low-dose prednisolone. Acta Derm Venereol. 2001; 81:134-6.

76. Hansen LS, Silverman S Jr, Daniels TE: The differential diagnosis of pyostomatitis vegetans and its relation to bowel disease. Oral Surg Oral Med Oral Pathol. 1983;55:363-73.

77. Wolz MM, Camilleri MJ, McEvoy MT, Bruce AJ: Pemphigus vegetans variant of IgA pemphigus, a variant of IgA pemphigus and other autoimmune blistering disorders. Am J Dermatopathol. 2013;35:e53-6.

78. Ahmed AR, Blose DA: Pemphigus vegetans. Neumann type and Hallopeau type. Int J Dermatol. 1984;23:135-41.

79. Cazanave P: Pemphigus chronique, general;forme rare de pemphigus foliace; mort; autopsie, altation du foie. Ann Maladies Peau Syph. 1844;1:208-10.

80. Castro RM, Proença NG: Similarities and differences between Brazilian wild fire and pemphigus foliaceus Cazenave. Hautarzt. 1982;33:574-7.

81. Kessler JB: Pemphigus foliaceus. JAMA. 1913;61:102-5.

82. Bilet S, Faucher F, Crickx B, Chosidow O, Belaïch S, Grossin $\mathrm{M}$, et al: Cazenave's pemphigus foliaceus: therapeutic difficulties. Aspects of transient acanthosis nigricans during healing. Ann Dermatol Venereol. 1988;115:1140-2.

83. Kormann N: Pemphigus. J Am Acad Dermatol. 1988;18:1219-38. 84. Bystryn JC, Rudolph JL: Pemphigus. Lancet. 2005;366:61-73.

85. Kazerounian S, Mahoney MG, Uitto J, Aho S: Envoplakin and periplakin, the paraneoplastic pemphigus antigens, are also recognized by pemphigus foliaceus autoantibodies. J Invest Dermatol. 2000;115:505-7.

86. Jiao D, Bystryn JC: Antibodies to desmoplakin in a patient with pemphigus foliaceous. J Eur Acad Dermatol Venereol. 1998;11:16972.

87. Ioannides D, Hytiroglou P, Phelps RG, Bystryn JC: Regional variation in the expression of pemphigus foliaceus, pemphigus erythematosus, and pemphigus vulgaris antigens in human skin. J Invest Dermatol.1991;96:159-61.

88. Igawa $\mathrm{K}$, Matsunaga $\mathrm{T}$, Nishioka $\mathrm{K}$ : Involvement of UVirradiation in pemphigus foliaceus. J Eur Acad Dermatol Venereol. 2004;18:216-7.

89. Kano Y, Shimosegawa M, Mizukawa Y, Shiohara T: Pemphigus foliaceus induced by exposure to sunlight. Report of a case and analysis of photochallenge-induced lesions. Dermatology. 2000;201:132-28.

90. Triftshauser C, Wypych J, Cloutier LC, Beutner EH: Flourescent antibody studies of pemphigus-like antibodies in burn sera. Ann N Y Acad Sci. 1971;177:227-33.

91. Castro RM, Proenca NG: Semelhancas e diferencas entre o fogo selvagem e o penfigo foliaceo de Cazanave. Similarities and differences between South American pemphigus foliaceus and cazanaves pemphigus foliaceus. An Bras Dermatol. 1983;53:137-9. 92. Bastuji G, Souissi R, Blum L, Turki H, Nouira R, Jomaa B, et al: Comparative epidemiology of pemphigus in Tunisia and France: unusual incidence of pemphigus foliaceus in young Tunisian woman. J Invest Dermatol.1995;104:302-5.

93. Hans-Filho G, dos Santos, Katayama JH, Aoki V, Rivitti EA, Sampaio SAP, et al: An active focus of high prevalence of Fogo Selvagem on an amerindian reservations in Brazil. J Invest Dermatol. 1996;107:68-75.

94. Abreu Velez AM, Messias-Reason LJ, Howard MS, Roselino AM: Endemic pemphigus foliaceus over a century: part 1 North Am J Med Sci. 2010:2:51-9.

95. Abreu Velez AM, Roselino AM, Howard MS, Messias-Reason LJ: Endemic pemphigus foliaceus over a century: part 2. North Am J Med Sci. 2010:2:114-25. 
96. Abréu Vélez AM, Abréu Vélez CE, Patiño PJ, Montoya-Maya F, Bollag BW: The tryptic cleavage product of the mature form of the bovine desmoglein 1 ectodomain is one of the antigen moieties immunoprecipitated by all sera from symptomatic patients affected by a new variant of endemic pemphigus. Eur Journal Dermatol. 2003;359-66.

97. Abreu Velez AM, Villa-Robles E, Howard MS: A new variant of endemic pemphigus foliaceus in El-Bagre, Colombia: the HardyWeinberg-Castle law and linked short tandem repeats. North Am J Med Sci. 2009;1:169-79.

98. Hisamatsu Y, Abreu Velez AM, Amagai M, Ogawa MM, Kanzaki T, Hashimoto T: Comparative study of autoantigen profile between Colombian and Brazilian types of endemic pemphigus foliaceus by various biochemical and molecular biological techniques. J Dermatol Sci. 2003;32:33-41.

99. Abréu Vélez AM, Hashimoto T, Tobón S, Londoño ML, Montoya F, Bollag WB, et al: A unique form of endemic pemphigus in Northern Colombia. J Am Acad Dermatol. 2003;4:609-14.

100. Cerna M, Fernandez-Vina M, Friedman H, Moraes JR, Diaz LA, Stastny P: Genetic markers for susceptibility to endemic Brazilian pemphigus foliaceus (fogo selvagem) in Xavante indians. Tissue Antigens. 1993;42:138-40.

101. Abreu Velez AM, Howard MS, Gao W, Grossniklaus HE, Jiao Zhe, Arias LF, et al: Varicella-zoster virus (VZV), and alpha 1 antitrypsin: a fatal outcome in a patient affected by endemic pemphigus. Int J Dermatol. 2012;51:809-16.

102. Gonçalves GA, Brito MM, Salathiel AM, Ferraz TS, Alves D, Roselino AM: Incidence of pemphigus vulgaris exceeds that of pemphigus foliaceus in a region where pemphigus foliaceus is endemic: analysis of a 21-year historical series. An Bras Dermatol. 2011;86:1109-12.

103. Abida O, Mahfoudh N, Kammoun A, Gaddour L, Hakim F, Toumi A, et al: Polymorphisms of HLA microsatellite marker in Tunisian pemphigus foliaceus. Hum Immunol. 2013;74:104-9.

104. Assumpção TC, Eaton DP, Pham VM, Francischetti IM, Aoki V, Hans-Filho G, et al: An insight into the sialotranscriptome of Triatoma matogrossensis, a kissing bug associated with fogo selvagem in South America. Am J Trop Med Hyg. 2012;86:1005-14.

105. Qian Y, Jeong JS, Maldonado M, Valenzuela JG, Gomes R, Teixeira $\mathrm{C}$, et al: Brazilian pemphigus foliaceus anti-desmoglein 1 autoantibodies cross-react with sand fly salivary LJM11 antigen. J Immunol. 2012;189:1535-59.

106. Ribeiro JM, Valenzuela JG, Pham VM, Kleeman L, Barbian KD, Favreau AJ, et al: An insight into the sialotranscriptome of Simulium nigrimanum, a black fly associated with fogo selvagem in South America. Am J Trop Med Hyg. 2010;82:1060-75.

107. Kallel Sellami M, Ben Ayed M, Mouquet H, Drouot L, Zitouni M, Mokni M, et al: Anti-desmoglein 1 antibodies in Tunisian healthy subjects: arguments for the role of environmental factors in the occurrence of Tunisian pemphigus foliaceus. Clin Exp Immunol. 2004; 137:195-200.

108. Cunha PR, Bystryn JC, Medeiros EP, de Oliveira JR: Sensitivity of indirect immunofluorescence and ELISA in detecting intercellular antibodies in endemic pemphigus foliaceus (Fogo Selvagem). Int J Dermatol. 2006;45:914-8.

109. Cordel N, Maire C, le Gilbert D, Courville P, Tressières B: Afro-Caribbean pemphigus: epidemiological data from a 5-year prospective study on the island of Guadeloupe (French West Indies). Int J Dermatol. 2013;52:1357-60.

110. Ortega-Loayza AG, Ramos W, Gutierrez EL, Jimenez G, Rojas I, Galarza C: Endemic pemphigus foliaceus in the Peruvian Amazon. Clin Exp Dermatol. 201338:594-600.

111. Robledo MA. Chronic methyl mercury poisoning may trigger endemic pemphigus foliaceus ,fogo selvagem”. Med Hypotheses. 2012;78:60-66.
112. Abreu-Velez AM, Howard MS, Jiao Z, Gao W, Yi H, Grossniklaus HE, et al: Cardiac autoantibodies from patients affected by a new variant of endemic pemphigus foliaceus in Colombia, South America. J Clin Immunol. 2011;31:985-97.

113. Abreu Velez AM, Yi H, Gao W, Smoller BR, Grossniklaus HE, Howard MS: Antibodies to pilosebaceous units along their neurovascular supply routes in a new variant of endemic pemphigus foliaceus in Colombia, South America. Eur J Dermatol. 2011;21:3715.

114. Senear FE, Usher B: An unusual trype of pemphigus combining features of lupus erythematosus. Arch Dermatol.1926;13:761-81.

115. Chorzelski T, Jablosnka S, Blaszcyk M: immunopathological investigation in the Senear-Usher syndrome (coexistance of pemphigus and lupus erythermatosus). Br J Derm; 1968;80:217.

116. Maize JC, Green D, Provost TT: Pemphigus foliaceus: a case with serologic features of Senear-Usher syndrome and other autoimmune abnormalities. J Am Acad Dermatol.1982;7:736-41.

117. Pérez-Pérez ME, Avalos-Díaz E, Herrera-Esparza R: Autoantibodies in senear-usher syndrome: cross-reactivity or multiple autoimmunity? Autoimmune Dis. 2012;2012:296214.

118. Orfanos CE, Gartmann H. Mahrle G: Pathogenesis of pemphigus erythematosus. Transformation of a chronic discoid erythematosus in a pemphigus erythematosus (Senear-Usher). Arch Dermatol Forsch. 1971;240:317-33.

119. Steffen C, Thomas D: The men behind the eponym: Francis E. Senear, Barney Usher, and the Senear-Usher syndrome. Am J Dermatopathol. 2003;25:432-6.

120. Jordon RE: An unusual type of pemphigus combining features of lupus erythematosus. by Senear and Usher, June 1926. Commentary: Pemphigus erythematosus, a unique member of the pemphigus group. Arch Dermatol.1982;118:723-42.

121. Bolgert M, Levy G, Mikol C: Eosinophilia in Duhring-Brocq disease and pemphigus.Bull Soc Fr Dermatol Syphiligr. 1953;60:1345 .

121. Ehlers G, Krause W: On the clinical picture of pemphigus serpiginosus HEBRA. Z Haut Geschlechtskr. 1968;43:85-90.

122. Jabloska S, Chorlezelski TP, Beutner EH, Chorzelska JF: Herpetiform pemphigus, a variable pattern of pemphigus. 1975. Int J Dermatol.14:353-9.

123. Maciejowska E, Jablonska S, Chorzelski T: Is pemphigus herpetiformis an entity? Int J Dermatol. 1987;26:571-7.

124. Jonquieres ED, Bonafina OA: Herpetiforme pemphigus. Med Cutan Ibero Lat Am. 1976;4:265-70.

125. Binet O, Girard J, Beltzer-Garelly E, Avram A, Césarini JP, AronBrunetière R: Pemphigus herpetiformis (eosinophilic spongiosis). Dermatologica. 1979;159:151-9.

124. Ishii K, Amagai M, Komai A, Ebihara T, Chorzelski TP, Jablonska $\mathrm{S}$, et al: Desmoglein 1 and desmoglein 3 are the target autoantigens in herpetiform pemphigus. Arch Dermatol. 1999;135:943-7.

125. Lever WF: Inflammatory skin diseases and hypereosinophilia. Z Hautkr. 1987;62:766-8, 771-2.

126. Rebora A: Shape and configuration of skin lesions: grouped herpetiform. Clin Dermatol. 2011;29:509-10.

127. Ohata C, Higashi Y, Yamagami J, Koga H, Ishii N, Kanekura T, et al: Coexistence of pemphigus herpetiformis with IgG Antibodies to desmocollin 1 and pemphigoid with $\mathrm{IgG}$ antibodies to BP180 C-terminal domain and Laminin $\gamma 2$. JAMA Dermatol. 2013;149:5024.

128. Sneddon IB, Wilkinson DS: Subcorneal pustular dermatosis. Br J Dermatol. 1956;68:385-94.

129. Huff JC, Golitz LE, Kunke KS: Intraepidermal neutrophilic IgA dermatosis. N Engl J Med. 1985;313:1643-5.

130. Varigos GA: Subcorneal pustulosis with IgA abnormalities in serum and small bowel mucosa: case report. Australas J Dermatol. 1979;20:75-7. 
131. Launay F, Albès $B$, Bayle $P$, Carrière $M$, Lamant L, Bazex J: Sneddon-Wilkinson disease. Four cases report. Rev Med Interne. 2004;25:154-9.

132. Kuan YZ, Chiou HT, Chang HC, Chan HL, Kuo TT: Intraepidermal neutrophilic IgA dermatosis. J Am Acad Dermatol. 1990;22:917-9.

133. Wallach D, Foldès C, Cottenot F: Subcorneal pustulosis, superficial acantholysis and monoclonal IgA. Ann Dermatol Venereol. 1982;109:959-63.

144. Cheng S, Edmonds E, Ben-Gashir M, Yu RC: Subcorneal pustular dermatosis: 50 years on. Clin Exp Dermatol. 2008;33:22933.

145. Dmochowski M, Hashimoto T, Chidgey MA, Yue KK, Wilkinson RW, Nishikawa T, et al: Demonstration of antibodies to bovine desmocollin isoforms in certain pemphigus sera. $\mathrm{Br} \mathrm{J}$ Dermatol. 1995; 133:519-25

146. Hashimoto T, Kiyokawa C, Mori O, Miyasato M, Chidgey MA, Garrod DR, et al: Human desmocollin 1 (Dsc1) is an autoantigen for the subcorneal pustular dermatosis type of IgA pemphigus. J Invest Dermatol. 1997;109:127-31.

147. Tsuruta D, Ishii N, Hamada T, Ohyama B, Fukuda S, Koga H, et al: IgA pemphigus. Clin Dermatol. 2011;29:437-42.

148. Düker I, Schaller J, Rose C, Zillikens D, Hashimoto T, Kunze J: Subcorneal pustular dermatosis-type IgA pemphigus with autoantibodies to desmocollins 1, 2, and 3. Arch Dermatol. 2009; 145:1159-62.

149. Kárpáti S, Amagai M, Liu WL, Dmochowski M, Hashimoto $\mathrm{T}$, Horváth A: Identification of desmoglein 1 as autoantigen in a patient with intraepidermal neutrophilic IgA dermatosis type of IgA pemphigus. Exp Dermatol. 2000;9:224-8.

150. Ongenae KC, Temmerman LJ, Vermander F, Naeyaert JM: Intercellular IgA dermatosis. Eur J Dermatol. 1999;9:85-94.

152. Wallach D: Intraepidermal IgA pustulosis. J Am Acad Dermatol. 1992;27:993-1000.

153. Hashimoto T, Komai A, Futei Y, Nishikawa T, Amagai M: Detection of IgA autoantibodies to desmogleins by an enzymelinked immunosorbent assay: the presence of new minor subtypes of IgApemphigus. Arch Dermatol. 2001;137:735-8.

153. Ebihara T, Hashimoto T, Iwatsuki K, Takigawa M, Ando M, Ohkawara A, et al: Autoantigens for IgA anti-intercellular antibodies of intercellular IgA vesiculopustular dermatosis. J Invest Dermatol. 1991;97:742-5.

154. Abreu Velez AM, Smith JG Jr, Howard MS: Subcorneal pustular dermatosis an immnohisto-pathological perspective. Int J Clin Exp Pathol. 2011;4:526-9.

155. Korman NJ, Eyre RW, Zone J, Stanley JR: Drug induced pemphigus: autoantibodies directed against the pemphigus antigen complexes are present in penicillamine and captopril-induced pemphigus. J Invest Dermatol.1991;96:273-6.

156. Feng S, Zhou W, Zhang J, Jin P: Analysis of 6 cases of druginduced pemphigus. Eur J Dermatol. 2011;21:696-9.

157. Brenner S, Goldberg I: Drug-induced pemphigus.Clin Dermatol. 2011;29:455-77.

158. Landau M, Brenner S: Histopathologic findings in drug-induced pemphigus. Am J Dermatopathol. 1997;19:411-4.

159. Tang X, Zhang X: Drug-induced pemphigus after six years of treatment with phenytoin and carbamazepine. Int J Dermatol. 2012;51:485-6.

160. Feng S, Zhou W, Zhang J, Jin P: Analysis of 6 cases of druginduced pemphigus. Eur J Dermatol. 2011;21:696-9.

161. Brenner S, Goldberg I: Drug-induced pemphigus. Clin Dermatol. 2011;29:455-7.

162. Cozzani E, Rosa GM, Drosera M, Intra C, Barsotti A, Parodi A: ACE inhibitors can induce circulating antibodies directed to antigens of the superficial epidermal cells. Arch Dermatol Res. 2011;303:32732 .
163. Qian Y, Prisayanh P, Andraca E, Qaqish BF, Aoki V, HansFilhio G, et al: Cooperative Group on Fogo Selvagem Research. $\operatorname{IgE}$, IgM, and IgG4 anti-desmoglein 1 autoantibody profile in endemic pemphigus foliaceus (fogo selvagem). J Invest Dermatol. 2011;131:985-7.

167. Bruns GR, Ablin RJ: IgE in pemphigus. Arch Dermatol. 1977;113:1461.

168. Nagel A, Lang A, Engel D, Podstawa E, Hunzelmann N, de Pita $\mathrm{O}$, et al: Clinical activity of pemphigus vulgaris relates to $\operatorname{IgE}$ autoantibodies against desmoglein 3. Clin Immunol. 2009;134:320 30.

169. Abreu-Velez AM, Howard MS, Hashimoto T, Grossniklaus HE: Human eyelid meibomian glands and tarsal muscle are recognized by autoantibodies from patients affected by a new variant of endemic pemphigus foliaceus in El-Bagre, Colombia, South America. J Am Acad Dermatol. 2010;62:437-47.

170. Nagel A, Lang A, Engel D, Podstawa E, Hunzelmann N, de Pita $\mathrm{O}$, et al: Clinical activity of pemphigus vulgaris relates to $\operatorname{IgE}$ autoantibodies against desmoglein 3. Clin Immunol. 2010;134:32030.

171. Anhalt GJ, Kim SC, Stanley JR, Korman NJ, Jabs DA, Cory M, et al: Paraneoplastic pemphigus. An autoimmune mucocutaneous disease associated with neoplasia. N Engl J Med. 1990;323:1729-35. 172. Bystryn J-C, Hodak E, Gao S-Q, Chuba JV, Amorosi EL: A paraneoplastic mixed bullous skin disease associated with anti-skin antibodies and a B-cell lymphoma. Arch Dermatol 1993;129:870-5.

173. Kiyokawa C: Envoplakin and periplakin are the paraneoplastic pemphigus antigens. Kurume Med J. 1999;46:71-8.

174. Oursler JR, Labib RS, Ariss-Abdo L, Burke T, O'Keefe EJ, Anhalt GJ. Human autoantibodies against desmoplakins in paraneoplastic pemphigus. J Clin Invest 1992; 89:1775-82.

175. Abreu Velez AM, Howard MS: Diagnosis and treatment of cutaneous paraneoplastic disorders. Dermatol Ther. 2010;23:662-75. 176. Prakken JR, Woerdeman MJ: Paraneoplastic pemphigus and Pemphigus Vulgaris. Ned Tijdschr Geneeskd. 1954;30;98:3127-35.

177. Plewig G, Jansen T, Jungblut RM, Röher HD: Castleman tumor, lichen ruber and pemphigus vulgaris: paraneoplastic association of immunological diseases? Hautarzt. 1990;41:662-70.

178. Panteleeva GA: Paraneoplastic bullous dermatoses. Vestn Dermatol Venerol. 1990;50-2.

179. Belsan I, Jirásek L, Kratochvílová M, Bohut V: Pemphigus vulgaris as a paraneoplastic manifestation of bronchogenic carcinoma (author's transl)]. Cesk Dermatol. 1980;55:314-7.

180. Bohatka L, Alfody G: Oral manifestations of paraneoplastic syndrome. Fogorv Sz. 1976;69:264-8.

181. Morandi GA, Panerai A, Bongi G: Paraneoplastic syndromes. 3. Clinical contribution to the knowledge of paraneoplastic pemphigoid]. Riv Crit Clin Med. 1964;64:498-508.

182. Kim SC, Kwon YD, Lee IJ, Chang SN, Lee TG: R. Envoplakin is a component of the antigen complex in paraneoplastic pemphigus. J Invest Dermatol. 1997abs;108:581.

183. Kim SC, Kwon YD, Lee IJ, Chang SN, Lee TG: cDNA cloning of the $210-\mathrm{kDa}$ paraneoplastic pemphigus antigen reveals that envoplakin is a component of the antigen complex. J Invest Dermatol. 1997;109:365-9.

184. Proby C, Fujii Y, Owaribe K, Nishikawa T, Amagai M: Human autoantibodies against $\mathrm{HD} 1 /$ plectin in paraneoplastic pemphigus. $\mathrm{J}$ Invest Dermatol.1999;112:153-6.

185. Mahoney MG, Aho S, Uitto J, Stanley JR: The members of the plakin family of proteins recognized by paraneoplastic pemphigus antibodies include periplakin. J Invest Dermatol. 1998;111:308-13.

186. Schepens I, Jaunin F, Begre N, Läderach U, Marcus K, Hashimoto T, et al: The protease inhibitor alpha-2-macroglobulinlike- 1 is the p170 antigen recognized by paraneoplastic pemphigus autoantibodies in human.PLoS One. 2010;5:e12250. 
187. Bech R, Baumgartner-Nielsen J, Peterslund NA, Steiniche T, Deleuran M, d'Amore F: Alemtuzumab (alz) is effective against severe chronic lymphocytic leukemia-associated paraneoplastic pemphigus (pnp). Br J Dermatol. 2013;169:469-72.

188. Grunwald MH, Zamora E, Avinoach I, Holcberg G, Azaz B, Katz M, et al: Pemphigus neonatorum. Pediatr Dermatol. 1993;10:169-70. 189. Panko J, Florell SR, Hadley J, Zone J, Leiferman K, Vanderhooft S: Neonatal pemphigus in an infant born to a mother with serologic evidence of both pemphigus vulgaris and gestational pemphigoid. J Am Acad Dermatol. 2009;60:1057-62.

200. Dancer SJ, Poston SM, East J, Simmons NA, Noble WC: An outbreak of pemphigus neonatorum. J Infect. 1990;20:73-82.

201. Winfield LD, White SD, Affolter VK, Renier AC, Dawson D, Olivry T, et al: Pemphigus vulgaris in a Welsh pony stallion: case report and demonstration of antidesmoglein autoantibodies. Vet Dermatol. 2013;24:269-e60.

202. Medleau L, Dawe DL, Scott DW: Complement immunofluorescence in sera of dogs with pemphigus foliaceus. Am J Vet Res. 1987;48:486-7.

203. Scott DW: Pemphigus vegetans in a dog. Cornell Vet. 1977;67:374-84.

204. Oberkirchner U, Linder KE, Dunston S, Bizikova P, Olivry T: Metaflumizone-amitraz (Promeris)-associated pustular acantholytic dermatitis in 22 dogs: evidence suggests contact drug-triggered pemphigus foliaceus. Vet Dermatol. 2011;22:436-48.

204. Lever WF, Schaumburg-Lever G: Treatment of pemphigus vulgaris. Results obtained in 84 patients between 1961 and 1982. Arch Dermatol. 1984;120:44-7.

205. Lapidoth M, David M, Ben-Amitai D, Katzenelson V, Lustig S, Sandbank M: The efficacy of combined treatment with prednisone and cyclosporine in patients with pemphigus: preliminary study. J Am Acad Dermatol. 1988;30:752-7.

206. Green MG, Bystryn JC: Effect of intravenous immunoglobulin therapy on serum levels of IgG1 and IgG4 antidesmoglein 1 and antidesmoglein 3 antibodies in pemphigus vulgaris. Arch Dermatol. 2008; 144:1621-4.

207. Tan-Lim R, Bystryn JC: Effect of plasmapheresis therapy on circulating levels of pemphigus antibodies. J Am Acad Dermatol. 1990;22:35-40.
208. Director W, Rogachefsky H: Pemphigus folicaceus: response to corticotropin (ACTH) and cortisone; appearance of acanthotic lesions. AMA Arch Derm Syphilol. 1953;68:469-70.

209. lszewska M, Kolacinska-Strasz Z, Sulej J, Labecka H, Cwikla $\mathrm{J}$, Natorska U, et al. Efficacy and safety of cyclophosphamide, azathioprine, and cyclosporine (ciclosporin) as adjuvant drugs in pemphigus vulgaris. Am J Clin Dermatol. 2007;8:85-92.

210. Bystryn JC, Steinman NM: The adjuvant therapy in pemphigus. Arch Dermatol. 1996; 132:203-12.

211. Macdonal C: Immunomodulatory and cytotoxic agents in dermatology. Marcel Dekker Inc (Eds). Blackwell Scientific Ltd, 1996.

212. Basset N, Guillot B, Michel B, Meynadier J, Guilhou JJ: Dapsone as initial treatment in superficial pemphigus. Arch Dermatol. 1987;123:783-5.

213. Tappeiner G, Steiner A: High-dosage intravenous gamma globulin: therapeutic failure in pemphigus and pemphigoid. J Am Acad Dermatol. 1989;20:684-5.

214. Rook AH, Heald PW, Nahass GT: Treatment of autoimmune disease with extracorporal photochemotherapy: pemphigus vulgaris: preliminary report. Yale J Biol Med.1989;62:647-52.

215. Beckers RCY, Brand A, Vermeer BJ, Boom BW: Adjuvant high-dose intravenous gammaglobulin in the treatment of pemphigus and bullous pemphigoid: experience in six patients. Br J Dermatol.1996;133:289-93.

216. Harman KE, Albert S, Black MM: Guidelines for the management of pemphigus vulgaris. Br J Dermatol. 2003;149:926-37.

217. Wojnarowska F, Kirtschig G, Highet AS, Venning VA, Khumalo NP.: Guidelines for the management of bullous pemphigoid. Br J Dermatol. 2002;147:214-21.

218. Pasricha JS, Thanzama J, Khan UK: Intermittent high-dose dexamethason-cyclophosphamide therapy for pemphigus. $\mathrm{Br} \mathrm{J}$ Dermatol. 1988;119:73-7.

219. Pandya AG, Sontheimer RD: Treatment of pemphigus vulgaris with pulse intravenous cyclophosphamide. Arch Dermatol. 1992;128:1626-30.

220. Hymes SR, Jordon RE: Pemphigus foliaceus: use of antimalarial agents as adjuvant therapy. Arch Dermatol. 1992;128:1462-4.

Copyright by Ana Maria Abreu Velez, et al. This is an open access article distributed under the terms of the Creative Commons Attribution License, which permits unrestricted use, distribution, and reproduction in any medium, provided the original author and source are credited. 